
\title{
25 Research Square \\ Drivers of Microbial Community Structure in Surface Sediment Aross Bohai Sea
}

lei chen ( $\nabla$ stepper95@163.com )

School of Life Science, Qufu Normal University, Qufu, Shandong 273165, China.

Yuntao Li

Institute of Soil Science

Mingpeng Wang

Qufu Normal University

Weitao Shang

Yantai Institute of Coastal Zone Research

Jianhui Tang

Yantai Institute of Coastal Zone Research

David Jones

Bangor University

Fanghua Liu

Yantai Institute of Coastal Zone Research

\section{Research Article}

Keywords: geography, microbial community composition, Iron-Reducing Bacteria (IRB), salinity, magnetic susceptibility

Posted Date: December 7th, 2020

DOI: https://doi.org/10.21203/rs.3.rs-116302/v1

License: (1) This work is licensed under a Creative Commons Attribution 4.0 International License.

Read Full License 


\section{Abstract}

Background: Microbial spatial distribution has been widely investigated in sediment. However, there is poorly available information on microbial distribution patterns in sediment of Bohai Sea coastal zone.

Results: Here, we investigated the bacterial community composition and diversity in riverine and marine surface sediment around and in the Bohai Sea using high-throughput sequencing. Bacterial communities mainly comprised Proteobacteria, Bacteroidetes, and Firmicutes. Salinity, dissolved oxygen, pH, and magnetic susceptibility played the main role in determining bacterial a-diversity and community composition in this region. Of the total bacterial community composition variation, environmental factors (explained $29.41 \%$ of the total microbial community composition variation) played a more important role than spatial variables (explained 3.03\%) in conditioning the bacterial community composition.

Meanwhile, the significantly pure spatial effect and distance-decay tendency suggested that dispersal limitation was also an influential factor in shaping the bacterial biogeographical pattern. The presence of magnetite center might shape the geographical distribution of five genera Lactococcus, Clostridium, Caulobacter, Gillisia and Sphingomonas probably by affecting their iron-related geochemical cycle.

Conclusion: Our results may provide a better understanding of present-day bacterial biogeography and the correlation between microbial communities and key environmental variables in a typical coastal area. Depending on these information, coastal resources could be efficiently predicted, assessed and used.

\section{Background}

Microbial spatial distribution has been widely studied in coastal sediments [1, 2]. Environmental variables such as salinity, $\mathrm{pH}$, and dissolved oxygen (DO), and spatial factors such as geographical distance are critical to microbial diversity and community composition [3-7]. There is little available information regarding the effect of environmental variables on microbial distribution patterns in Bohai Sea sediment.

The Bohai Sea is a large semi-enclosed shallow water basin (15-30 m depth), with an area of $77 \times 10^{3}$ $\mathrm{km}^{2}$ [8]. It contains the Bohai Bay, Liaodong Bay, and Laizhou Bay, and connects with the outer ocean through the Bohai Strait. The main terrigenous inputs to the sea include surface sediments, nutrients, and contaminants from the extensive network of rivers that feed into the Bohai Sea [9]. For example, over 40 rivers run into the Bohai Sea from the three main bays. This coastal region is considered one of the most densely urbanized and industrialized zones in the country. The coastal regions contain the sediments of mainly terrestrial provenance arising from river discharges, inlets, and estuaries, as a result of run-off from adjacent land [9].

In estuarine sediment, an abundance of iron rich minerals exists. However, although iron is essential for the survival of all living organisms, few studies take factors related to iron such as iron content and magnetic susceptibility into consideration when exploring the microbial community composition of these sediments. On the one hand, very little information regarding the magnetic susceptibility influence is currently available in published literature, and as our study site occurs in Bohai Sea. There is poorly 
available information on microbial distribution patterns in sediment of Bohai Sea coastal zone. There is a joint of three fault zones (the Tanlu, Liaocheng-Lankao, and Zhangjiakou-Penglai fault zones) within the Bohai Sea and sedimentary magnetite distribution in the gulf of Bohai Sea showed the highest contents of magnetite at site $\left(120.4^{\circ} \mathrm{E}, 39^{\circ} \mathrm{N}\right)[10,11]$, close to the joint of the three fault zones. This provides an ideal opportunity to examine well-established variables that influence microbial community composition and distribution. On the other hand, magnetic susceptibility and the abundance of iron rich minerals are often used as predictors for iron reducing bacteria presence [12-15] and indicate pollution level caused by anthropogenic use and magnetic grain inputs [16]. Furthermore, it reflects the influence of human activities to some extent [16]. Thus, taking the magnetic susceptibility factor into consideration might well link microbial composition, geographical distribution with the presence of magnetite, human activities and environmental health.

Recent studies suggest that microbial communities are connected to both environmental conditions and spatial factors when investigating the microbial biogeography [17-20]. However, there is little available information on microbial distribution patterns in Bohai Sea sediment, much less spatially comprehensive surveys on the relative importance of these factors in Bohai Sea sediment. Here, we conducted highthroughput sequencing to explore the biogeographic patterns of microbial communities in surface sediments collected from estuaries and offshore within the Bohai Sea to (i) study the relationship between environmental variables including magnetic characters and microbial community composition; (ii) investigate the microbial distribution pattern in a typical coastal area; and (iii) assess the relative importance of environmental and spatial factors in shaping bacterial community composition in the Bohai Sea. We hope these assessments would help further development and utilization of coastal resources.

\section{Results}

\section{Environmental variables across the coastal zone}

A total of 158 sediment samples were obtained in this study, including 34 sediment samples from rivers entering the Bohai Sea and 124 sediment samples from the seafloor (Fig. 1a). Salinity, DO, magnetic susceptibility (mainly low-frequency susceptibility values, $\chi \mathrm{lf}$ ), and $\mathrm{pH}$ from 124 sites sampled across the Bohai Sea were detected (Fig. 1b). Based on their magnetic susceptibility profiles, 19 of these sites were chosen for further microbial community analysis, including 16 sites whose sediments possessed high $\chi$ lf values (near the Daliao, Liao, Liugu, and Sha Rivers) and three sites near the Yellow River whose sediments had low $\chi$ If values. The environmental variables values are shown in Table S1. In all measured environmental variables, only Fe was spatially correlated (Mantel tests, Table S2).

\section{Correlations between microbial diversity and environmental variables}


Based on the high-throughput sequencing data of the 16S rRNA gene, microbial diversity analysis of 24 locations (sediment A and B) (Table S2) provided 417,896 high quality bacterial sequences, averaging between 7,083 and 64,605 sequences per sample.

Significant effects of environmental variables on the a-diversity of microbial communities were distinguished by correlation analysis (Table 1 ). Sediment salinity was significantly correlated with the Chao1 index $(r=0.254, P=0.012), \mathrm{S}$ index $(r=0.303, P=0.005)$, and $\mathrm{H}^{\prime}$ index $(r=0.234, P=0.017)$. The Chao1 index $(r=0.188, P=0.034)$ and $S$ index $(r=0.246, P=0.014)$ showed a positive correlation with the DO content of sea water collected near the sea floor. The Fe content $(r=0.236, P=0.016)$ also showed a significant correlation with $\mathrm{H}^{\prime}$ index. There were no significant correlations between other measured characteristics and indices.

\section{Distribution of dominant microbial communities}

Analysis of microbial communities from 19 locations based on high-throughput sequencing data of the 16S rRNA gene showed that the major phyla included Proteobacteria (36.5-58.6\%), Bacteroidetes (5.3$37.6 \%$ ), and Firmicutes $(0.36-36.3 \%$ ) (Fig. 2a), which accounted for $49.3-84.1 \%$ of all bacterial sequences.

NMDS analysis of the OTUs from the 19 locations showed a considerably high amount of scatter and significant differences in bacterial community composition between estuarine locations (Fig. 2b). Significant differences between estuary and marine sediment separated by salinity were also observed. Individuals from marine sediment with high salinity tended to be clustered, indicating a high degree of microbial community similarity among marine sediment.

\section{Environmental determinants of bacterial community composition}

RDA showed that sediment salinity, DO, pH, and $x$ lf have strong effects (longer arrows) in shaping bacterial community composition (Fig. 2b). TOC exhibited an opposite trend to $\chi$ If. The first canonical axis (RDA1) explained $22.2 \%$ of the variation and the second canonical axis (RDA2) explained a further $18.6 \%$ of the variation. These results suggest that sediment salinity, DO, $\chi \mathrm{lf}, \mathrm{TOC}$, and pH could be good predictors of bacterial community composition variation.

Mantel tests showed that $\beta$-diversity of the total community was significantly correlated with salinity $(r=$ $0.680, P=0.001), \mathrm{pH}(r=0.462, P=0.001), \mathrm{DO}(r=0.528, P=0.001)$, and $\chi \mathrm{lf}(r=0.388, P=0.006)$ (Table 1$)$, even when the geographic distance was controlled in partial Mantel tests (Table 1). Salinity, DO, $\mathrm{pH}$, and $\chi$ If were the strongest environmental drivers of $\beta$-diversity, which was confirmed by both multiple regressions on a distance matrix and permutational analyses of variance on a distance matrix (Table 2). As in the Mantel test results outlined in table 1, total community structure was driven mainly by salinity. The strongest influence of salinity was also observed with respect to the bacterial major phyla, since the relative abundances of Proteobacteria $\left(r^{2}=0.248, P=0.030\right)$ and Bacteroidetes $\left(r^{2}=0.632, P<0.001\right)$ across all sites increased significantly along the salinity gradient (Fig. 3 ). The relative abundances of 
Chloroflexi $\left(r^{2}=0.336, P=0.009\right)$, Actinobacteria $\left(r^{2}=0.367, P=0.006\right)$, Cyanobacteria $\left(r^{2}=0.232, P=\right.$ $0.036)$, and Chlorobi $\left(r^{2}=0.244, P=0.032\right)$ decreased with the salinity gradient (Fig. 3$)$.

DO, the additional factor strongly influencing bacterial community composition in Mantel test results was negatively correlated with respect to Proteobacteria $\left(r^{2}=0.465, P=0.001\right)$ and Bacteroidetes $\left(r^{2}=0.335, P\right.$ $=0.009$ ). The relative abundances of Proteobacteria and Bacteroidetes increased with elevated salinity and decreased with increased DO. DO, was positively correlated with Chloroflexi $\left(r^{2}=0.354, P=0.007\right)$, Actinobacteria $\left(r^{2}=0.564, P<0.001\right)$, and Cyanobacteria $\left(r^{2}=0.233, P=0.036\right)$ (Fig. 4a). The relative abundances of Chloroflexi, Actinobacteria, and Cyanobacteria decreased with the declining DO. The pH of water near the sea floor showed significant correlation with Planctomycetes $\left(r^{2}=0.281, P=0.019\right)$, Actinobacteria $\left(r^{2}=0.364, P=0.006\right)$, Fibrobacteres $\left(r^{2}=0.509, P<0.001\right)$, WS3 $\left(r^{2}=0.362, P=0.006\right)$, and Caldithrix $\left(r^{2}=0.266, P=0.024\right)$ (Fig. 4b). The relative abundances of Planctomycetes, Actinobacteria, and Fibrobacteres declined with the elevated $\mathrm{pH}$ values. The relative abundances of WS3 and Caldithrix increased with the elevated $\mathrm{pH}$ values.

In the process of detecting relationships between bacteria and magnetic susceptibility in natural environments, we found that If was significantly related to microbial community composition (Fig. 2c; Tables 1 and 2). Sediment $\chi$ lf values from all 24 sites are shown in Table S1, and ranged from $39.78 \times$ $10^{-7} \mathrm{~m}^{3} / \mathrm{kg}$ to $266.05 \times 10^{-7} \mathrm{~m}^{3} / \mathrm{kg}$. To explore the possible effects of $\chi$ lf on major taxonomic groups (top 20 phyla), a regression analysis was carried out. The results showed that relative abundances of Firmicutes $\left(r^{2}=0.334, P=0.010\right)$, Cyanobacteria $\left(r^{2}=0.332, P=0.010\right)$, and Actinobacteria $\left(r^{2}=0.262, P=\right.$

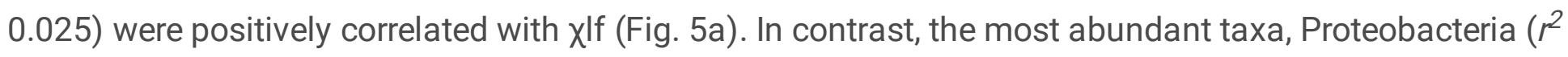
$=0.209, P=0.049$ ), responded to $\chi \mid \mathrm{f}$ in the opposite direction, being more abundant in sites where $\chi \mathrm{lf}$ values was lower. The relative abundances of Acidobacteria $\left(r^{2}=0.251, P=0.029\right)$, WS3 $\left(r^{2}=0.483, P<\right.$ $0.001)$, Chlorobi $\left(r^{2}=0.209, P=0.049\right)$, and OP8 $\left(r^{2}=0.295, P=0.016\right)$ also showed the opposite pattern (Fig. 5a).

Because $\chi$ If values are coupled to iron-reducing bacterial activity [21], we also analyze their relation in

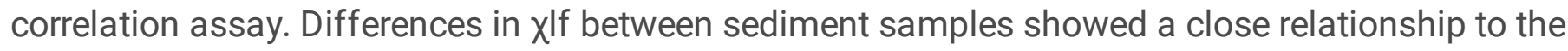
relative abundance of total identified Iron-Reducing Bacteria (IRB) (all reads classified as potential iron reducers) [22, 23] (Fig. 5b). Further, regression analysis showed that sediment $\chi$ If had a significant correlation with the relative abundances of total IRB $\left(r^{2}=0.334, P=0.013\right)$ (Fig. $\left.5 \mathrm{c}\right)$. This implies that magnetism in the environment could affect the diversity of total IRB.

\section{Effects of geographic distance on microbial community composition}

The relationship between geographic distance and Bray-Curtis dissimilarity between stations showed a clear distance-decay pattern $\left(R^{2}=0.0142, P<0.001\right)$ (Fig. 6$)$. This showed that community composition was remarkably correlated with geographic distance. 
The composition of the microbial community is not just affected by the distance between the points, but also likely by the distance from the center of the magnetite. Sedimentary magnetite distribution in the gulf of Bohai Sea showed the highest contents of magnetite at site $\left(120.4^{\circ} \mathrm{E}, 39^{\circ} \mathrm{N}\right)[10,11]$ located in the joint of three fault zones (the Tanlu, Liaocheng-Lankao, and Zhangjiakou-Penglai fault zones) within the Bohai Sea. In order to analyze the influence of the presence of magnetite center on the microbial community structure, we analyze the relationship between the relative abundances of top 15 genera of 2 cross-sections samples (Fig. 7a and b) and the distances from these samples to the center of magnetite. Five genera Lactococcus $(r=0.220, P=0.043)$, Caulobacter $(r=0.217, P=0.045)$, Gillisia $(r=0.366, P=$ 0.006), Clostridium ( $r=0.372, P=0.006)$ and Sphingomonas $(r=0.255, P=0.027$ ) (Table 3 ) were found correlated with the distances from these samples to the center of magnetite. This indicated that the presence of magnetite center might affect the geographical distribution of bacteria.

\section{Variation partitioning of microbial community composition}

Variation partitioning analysis showed that environmental and spatial variables could explain $37.45 \%$ of the total variation in microbial community composition (Fig. 8). Pure environmental effects explained $29.41 \%$ of the variation $(P<0.001)$, which was markedly higher than pure spatial effects $(3.03 \%, P<0.05)$. Approximately $5.01 \%$ of the variation was attributed to spatially structured environmental variation (the fraction jointly explained by environmental and spatial factors). The residual $62.55 \%$ of the variation was unexplained.

\section{Discussion}

\section{The important role of environmental variation in shaping bacterial $a$ - diversity}

In our study, microbial a-diversity was highly correlated with salinity, DO levels and total Fe content. Previously, increased salinity has been reflected by decreased microbial activity in the surface sediments of the Qinghai-Tibetan lakes [3], corroborating our findings that salinity shapes microbial diversity. DO was also documented to be the primary driving force in mine drainage habitats, related to metabolism associated with oxygen [24], and DO may play a crucial role in taxonomic diversity on a small (vertical) scale $[5,25,26]$. Thus, salinity and DO may have the same profound impacts on shaping microbial adiversity in this study. Although total Fe content had a weaker effect than salinity and DO in our research regions, it is considered one of three factors which significantly affected the diversity index, implying the potential importance of Fe-containing mineral (eg. high Xlf magnetite) for shaping microbial diversity in sediments.

\section{Environmental variation influenced microbial community composition}


In this study, community composition was correlated with environmental factors, and was affected by salinity, $\mathrm{pH}, \mathrm{DO}$, and $\chi \mathrm{lf}$. From these findings we can infer that environmental variables may be crucial to shaping the microbial community composition. Salinity is well known to be a major contributor to microbial community structure and function $[25,26]$. The important role of salinity in bacterial communities has been found across globally heterogeneous environments, and in the sedimentary ecosystems of Hypersaline Laguna Tebenquiche [5]. To be consistent with those findings, we observed the most significant correlations between salinity and bacterial community structure (Tables 1 and 2). Previous research has shown that bacterial communities in transition zones greatly vary geographically owing to sharp salinity gradients $[27,28]$. Thus, a possible reason for the influence of salinity on bacterial distribution is that our research sites focused on bacterial communities distributed in a geographic area with a wide salinity gradient, including estuaries, coastal margins, and an open sea, where salinity values differ greatly. Additionally, all living things need energy and metabolize. Salinity is related to osmotic pressure, which changes the intracellular membrane structure and affects microbial energy cost and metabolic pathways $[29,30]$. In this study, different energy cost and metabolic pathways are more adaptable to different salinity. Then certain bacteria are selected and they survive in this region with definite salinity. Taken together, these findings suggest that salinity is a universal predictor of bacterial distribution.

After salinity, sediment DO concentration was also found to be critical in shaping microbial community structure (Fig. 2c; Tables 1 and 2). The dominant phyla in this region were Proteobacteria and Bacteroidetes (Fig. 2a), which also represent the dominant phyla in the sediments of the eastern Mediterranean Sea [31]. In this study, Proteobacteria, Bacteroidetes, Chloroflexi, Actinobacteria, and Cyanobacteria were strikingly correlated with salinity and DO (Figs. 3 and 4). The tendency of the relative abundances of these five phyla to vary with salinity was opposite to their tendency to change with DO. The relative abundances of Proteobacteria and Bacteroidetes increased with elevated salinity and decreased with increased DO. This implied that the dominant phyla, Proteobacteria and Bacteroidetes, in the tested sedimentary regions may prefer sediment environments with high salinity and low DO. The relative abundances of Chloroflexi, Actinobacteria, and Cyanobacteria decreased with elevated salinity and decreased with the declining DO. This indicated that these three phyla prefer to inhabit shallowestuary sediment with low salinity and high DO.

In this study, we also found the $\mathrm{pH}$ values of the Bohai Sea to be another important environmental variable influencing bacterial community structure. In arctic soils [32] and lake sediments [4], pH has also been strongly related to the bacterial community structure. Here, the relative abundances of Planctomycetes, Actinobacteria, and Fibrobacteres decreased with elevated $\mathrm{pH}$ values. The relative abundances of WS3 and Caldithrix increased with elevated $\mathrm{pH}$ values. The $\mathrm{pH}$ values from the deepest water samples showed a significant correlation with these five phyla, indicating that the $\mathrm{pH}$ value is a predictor of bacterial community structure. Therefore, these findings indicate that environmental heterogeneity (including salinity, $\mathrm{DO}$, and $\mathrm{pH}$ ) was the predominant factor shaping the community composition of benthic bacteria in the Bohai Sea. 
$\mathrm{pH}$ would increase during the initial degradation of algal derived organic matter [33-35]. The RDA assay showed that TOC was positively associated with $\mathrm{pH}$, possibly because surface sediments contain a higher proportion of labile algal derived aliphatic organic matter and more anions [33-35]. Meanwhile, sea sediments contain considerable clay. Restricted aeration in clay reduces the rate of organic matter oxidation and protects it from decomposition [36]. These indicated that the studied sediment in our study might contain lots of fresh organic matter with little decomposition because of limited aeration.

In our study, Proteobacteria was the most abundant group of bacteria. When surface sediments contain higher proportions of organic matter, Proteobacteria and Bacteroidetes are often prominently detected during the initial degradation of algal derived organic matter in marine sediments [33-35]. The dominant members of Bacteroidetes in the surface sediments of our study site have been consistently enriched, as seen in previous studies [34,37]. Because Cyanobacteria is documented to be the main participant and contributor to primary productivity of the global carbon cycle [38, 39]. The occurrences of Bacteroidetes and Cyanobacteria in the surface sediment suggest that they may better survive in areas rich in fresh organic matter.

In the current study, Xlf affected community composition of many phyla including Firmicutes, Cyanobacteria, Actinobacteria, and Proteobacteria. Cyanobacteria showed a positive correlation with $\chi$ If. That indicated $x$ lf could affect the growth patterns of ecologically important species such as Cyanobacteria, the main participants of primary productivity in the global carbon cycle. In sediment, available Fe is momentous for Cyanobacteria growth and Fe oxide minerals have the largest release potential [40]. Therefore, growth of Cyanobacteria is heavily influenced by Fe availability in all water bodies [41]. Then organic matter and the carbon cycle are also affected. But a negative relationship between TOC and Xlf or Fe were observed in the RDA assay indicated that organic matter produced were consumed. Numerous bacteria that are dependent on organic matter produced by Cyanobacteria will be influenced. $\chi$ lf values are coupled to iron-reducing bacterial activity [21]. In our study, we also found relative abundances of iron-reducing bacteria genera changed with $\chi$ lf values and were significant correlated with $\chi \mathrm{If}$ values (Fig. 5). Thus, in Bohai Sea organic matter could stimulate microbial iron related metabolism, and in return, lead to a microbial-driven change in magnetic susceptibility $[42,43]$ as showed by measurable $\chi \mathrm{lf}$ values.

\section{The roles of dispersal limitation in conditioning bacterial biogeography}

Of all measured environmental variables, only Fe was spatially correlated (Mantel tests, Table 4). However, important drivers in this study (salinity, pH, DO, and Xlf) were not significantly spatially correlated. These results indicated that local environmental conditions were not shaped spatially.

In addition, despite the fact that the magnetite content in the center of the Bohai Basin is high, the magnetic susceptibility does not show a correlation with this distance, which may be because sedimentary settling happens in a vertical manner from surface to deep, whereas magnetic susceptibility is determine as iron minerals form based on location on the Earth, in relation to magnetic north. But in top 
15 genera (Fig. 7) five genera Lactococcus, Clostridium, Caulobacter, Gillisia and Sphingomonas showed a clear correlation with the distance from the center of the magnetite (Table 3). This implies that the presence of magnetite might shape the geographical distribution of these genera, and most likely by affecting the iron-related geochemical cycle these genera participate in. Lactococcus is reported that it could participate in Fe (III) reduction during the external electron transfer mediated by sodium anthraquinone-2,6-disulphonate (AQDS) [44]. The mechanism may be possible that Lactococcus sp. uses a very small portion of regenerated reducing power NADH for the reduction of external electron acceptor $\mathrm{Fe}$ (III) to Fe (II) in anaerobic lactic fermentation [45]. Then Lactic acid produced by Lactococcus was used by Clostridium for Fe (III) reduction, because Clostridium could act as a lactic fermenter and $\mathrm{Fe}$ reducer [46,47]. Caulobacter is known to be involved in metal oxidation [48] by biosorption and metabolism against Fe [48]. That is one of the reasons why Caulobacter distribution is also affected. Sphingomonas during the decay of Cyanobacteria was identified as a microcystin-degrading bacterium [49]. Thus, its distribution might be adjusted according to iron presence. Gillisia was detected as siderophore producer in seawater or sand samples [50]. Siderophores are the metal-chelating agents that primarily function to capture the insoluble ferric iron from different habitats [50,51]. Numerous bacteria could not produce siderophores but have siderophore acceptors [50, 51]. Gillisia might assist other bacteria such as Cyanobacteria, Lactococcus, Clostridium and Caulobacter without siderophore generation capability for bioavailable iron release or absorption from Fe-containing minerals. Therefore, its geographical distribution also was impacted by the presence of magnetite. Of course, further work is needed to confirm this.

Environmental variables explained $29.41 \%(P<0.001)$ of the total microbial community composition variation higher than spatial factors $3.03 \%(P<0.05)$ in a variation partitioning analysis (Fig. 8$)$ indicating their significant and dominant contribution.

In the present study, dominant OTU patterns and whole community composition were markedly $(P<$ 0.001 ) correlated with geographical distance (Fig. 6). The results of the distance-decay pattern indicated that dispersal limitation may be another influential factor driving microbial biogeography. Dispersal could eliminate the distance-decay relationship by counteracting microbial compositional differentiation [52]. Limited dispersal should strengthen the distance-decay relationship [52], and the strength of correlation between dispersal limitation and microbial community composition relies on geographical distance [53] and organism size [54]. Limitations of microbial dispersal have been demonstrated at large [55] or intermediate (10-3000 km) spatial scales [53]. Dispersal limitation may exist in intermediate spatial scale the Bohai Sea (approximately $100 \mathrm{~km}$ ). Powerful dispersal limitations exist with increased cell size [56], the bacteria in the current study occurred within a relatively narrow size range, from $2-5 \mu \mathrm{m}$. This could help explain why the distance-decay curve inclined slightly, which is evidence of community variation purely constrained by spatial factors (3.03\%) (Fig. 8). This demonstrated that dispersal limitation was associated with microbial community composition, but was not the dominant factor in shaping microbial biogeography in the Bohai Sea. 
A large unexplained fraction (62.55\%) was still in the variation partitioning analysis, and included unmeasured environmental variables, local artificial effects, and random factors. However, it is unclear how these processes work as portions of variation.

\section{Conclusions}

Salinity was the crucial environmental factor for bacterial a-diversity in riverine and marine surface sediment around and in the Bohai Sea. Salinity, DO, pH, and Xlf were strikingly correlated with bacterial community composition in this region. Dispersal limitation made an important contribution in shaping the bacterial biogeographical pattern. Environmental factors (explained $29.41 \%$ of the total microbial community composition variation) played a more important role than spatial variables (explained $3.03 \%$ ) in varying microbial community composition. The presence of magnetite shapes the geographical distribution of five genera Lactococcus, Clostridium, Caulobacter, Gillisia and Sphingomonas by affecting the iron-related geochemical cycle these genera participate in.

Our study makes a significant contribution to the literature because it not only provides novel information about key environmental variables that influence the microbial distribution and community structure in a typical coastal area, it examines the effect of magnetic influence on microbial community composition as well in an area with special geological structures in earthquakes natural fault lines. Our work provided valuable information for studying the relationship between geological fault lines and microbial activities.

\section{Materials And Methods}

\section{Study area, sampling, and environmental variables}

Within the study region, we selected six large rivers, namely the Daliao River, Liao River, Liugu River, Shi River, Yellow River, and the Sha River. Fourteen marine sediment samples were taken at various locations across the sea to capture the areas influenced by these rivers, alongside a further 10 riverine sediment samples (Fig. 1a). These samples were used for the main microbial community analysis. In addition to these samples, a further 124 marine sediment samples were collected across the Bohai Sea to spatially map DO, pH, salinity, and low-frequency magnetic susceptibility (Xlf) (Fig. 1b).

During peak rainy season (Aug 23-29, 2014), marine surface sediment $(0-20 \mathrm{~cm}$ depth) were collected using a stainless steel grab sampler deployed off the side of the "Yi Xing" research vessel. Riverine sediment ( $0-20 \mathrm{~cm}$ depth) was collected using a stainless corer from areas of extensive sediment deposition. Representative samples were achieved by mixing three independent subsamples collected within a $5 \mathrm{~m}^{2}$ area. All sediment samples were split into two parts and stored at $-20{ }^{\circ} \mathrm{C}$ immediately after collection. Upon coming back to the laboratory, one part of each sample was stored in the dark and freeze-dried prior to chemical analysis. The other was stored at $-80^{\circ} \mathrm{C}$ until DNA extraction. 
Throughout the survey, a global positioning system was utilized to map all the sampling sites. The temperature, $\mathrm{DO}, \mathrm{pH}$, and salinity measurements for the seawater overlying each sediment sample were obtained in situ using a SBE 25plus Sealogger CTD (Sea-Bird Scientific Ltd., Bellevue, WA, USA) fitted with $10 \mathrm{~L}$ Niskin bottles. The biogeographic data and kriging maps were analyzed with ArcGIS v.10.0 spatial analyst tools (ESRI Inc., Redlands, CA, USA).

\section{Chemical analysis and magnetic characterization}

Chemical analyses were carried out on the Analysis and Testing Center of the Yantai Institute at Coastal Zone Research, Chinese Academy of Sciences. After digestion with aqua regia, sediment total iron content was determined using an ELAN DRC II ICP-MS (PerkinElmer, Waltham, MA, USA). After pretreatment with $1 \mathrm{M} \mathrm{HCl}$ to remove carbonates, total organic carbon (TOC) and total nitrogen (TN) were determined using a Vario MACRO cube elemental analyzer (Elementar Analysensysteme GmbH, Langenselbold, Germany). Xlf was measured using a MS2B magnetic susceptibility meter (Bartington Instruments Ltd., Witney, UK).

\section{Sediment DNA extraction}

For each sample, genomic DNA was extracted from $0.5 \mathrm{~g}$ of sediment the day after sampling using a FastDNA® SPIN Kit (MP Biomedicals, Santa Ana, CA, USA) according to the manufacturer's instructions. The extracted DNA was suspended in $50 \mu \mathrm{L}$ of TE buffer, quantified by spectrophotometer (Smart SpecPlus, Bio-Rad, Hercules, CA, USA), and stored at $-20^{\circ} \mathrm{C}$ until further use.

\section{High-throughput sequencing data processing}

PCR and amplicon library preparation for high-throughput sequencing was performed as previously reported $[32,57]$. The bacterial $16 \mathrm{~S}$ rRNA gene data were processed using the Quantitative Insights Into Microbial Ecology (QIIME) 1.9.1-dev pipeline [58] (http://www.qiime.org) with the default parameters, unless otherwise noted according to procedures in a previous study [10]. We assessed microbial adiversity using four metrics caculated with R software v3.4.4 (https://www.r-project.org): the Shannon index $\left(\mathrm{H}^{\prime}\right)[59]$, the Chao1 index [60], and the observed OTU richness (S) according to previously published procedures [10].

\section{Nucleotide sequence deposition}

All sequencing datasets were deposited in the National Center for Biotechnology Information (NCBI) Sequence Read Archive (http://trace.ncbi.nlm.nih.gov/Traces/sra/) with accession numbers SRP090609, SRP105317, and SRP089997 (SRS1697954, SRS1697958, and SRS1697961).

\section{Statistical analyses}

Redundancy analysis (RDA) and non-metric multidimensional scaling (NMDS) were used to relate community structure and sediment/water properties for the different locations. Regression analysis was conducted using Origin v8.1 software (OriginLab Corp., Northampton, MA, USA). The Spearman's rank correlations between environmental variables and geographic distance were derived from a Mantel test 
with 999 permutations [61]. Simple and partial Mantel tests (based on 999 permutations) were analyzed the relationship between environmental variables (Euclidean distance) and community composition (Bray-Curtis dissimilarity) with controlled geographic distance [62].

The contribution of each environmental variable on community composition was separately calculated using a permutational multivariate analysis of variance (PERMANOVA, 'adonis' function in vegan $\mathrm{R}$ package with 9999 random permutations), and multiple regression on distance matrices (MRM, 'MRM' function in ecodist R package with 9999 permutations) based on Bray-Curtis dissimilarity [63].

The relative importance of spatial and environmental variables in driving the microbial community was determined by variation partitioning [64]. The roles of spatial factors were estimated by the principal coordinates of neighbor matrices (PCNM) method [65]. We used the 'pack for' library forward-selection procedure [66] to select environmental variables. Then, the variation of the community composition was partitioned between the extracted PCNM spatial variables and selected environmental variables using a partial redundancy analysis, which decomposed community composition into fractions explained by pure environmental variables, pure spatial factors (PCNM variables), spatially structured environmental variation (shared fraction), and unexplained variation. All statistical analyses were performed using $R$ software v3.4.4 (https://www.r-project.org).

\section{Abbreviations}

IRB

Iron-Reducing Bacteria; DO:dissolved oxygen; DLH:Daliao River; LH:Liao River, LGH:Liugu River; SH:Shi River; YR:Yellow River; SH:Sha River; Xlf:low-frequency magnetic susceptibility; TOC:total organic carbon; TN:total nitrogen; QIIME:Quantitative Insights Into Microbial Ecology; RDA:Redundancy analysis; NMDS:non-metric multidimensional scaling; $H^{\prime}$ :Shannon index; S:the observed OTU richness; MRM:multiple regression on distance matrices; PERMANOVA:permutational multivariate analysis of variance; PCNM:principal coordinates of neighbor matrices; AQDS:sodium anthraquinone-2,6disulphonate

\section{Declarations}

\section{Acknowledgements}

The authors are very grateful to Dr. Huajun Zheng for his help in data analysis. Thanks to Dr. Zhaojie Zhang, Dr. Haiyan Chu, and Dr. Wei Lin for their assistance in the revision of the article, and Dr. Huang Guopei for his assistance in the sampling process.

\section{Funding}

This research was supported by Natural Science Foundation of Shandong Province (No. ZR2019QB018), Young Talents Invitation Program of Shandong Provincial Colleges and Universities (2019-6-1), Shandong Natural Science Fund for Distinguished Young Scholars (No. JQ201608) \the Young Scientists 
Fund (No. 41401285) and General Program (No. 41371257) of National Natural Science Foundation of China.

\section{Availability of data and materials}

The datasets generated during and/or analyzed during the current study are available from the corresponding author on request.

\section{Authors' contributions}

LC performed the experiments, analyzed the data and wrote the paper. YL, MW, WS and JT carried out the microbial community analysis. DLJ participated in the revision of manuscript. FL designed the experiments. All authors read and approved the final manuscript.

\section{Ethics approval and consent to participate}

Not applicable.

\section{Consent for publication}

Not applicable.

\section{Competing interests}

The authors declare that they have no competing interests.

\section{References}

1. Liu J, Yang H, Zhao M, Zhang X-H. Spatial distribution patterns of benthic microbial communities along the Pearl Estuary, China. Syst App/ Microbiol. 2014; 37(8):578-589.

2. Zhang W, Pan Y, Yang J, Chen H, Holohan B, Vaudrey J, Lin S, McManus GB. The diversity and biogeography of abundant and rare intertidal marine microeukaryotes explained by environment and dispersal limitation. Environ Microbiol. 2018; 20(2):462-476.

3. Yang J, Ma L, Jiang HC, Wu G, Dong HL. Salinity shapes microbial diversity and community structure in surface sediments of the Qinghai-Tibetan Lakes. Sci Rep-Uk. 2016; 6.

4. Xiong J, Liu Y, Lin X, Zhang H, Zeng J, Hou J, Yang Y, Yao T, Knight R, Chu H.Geographic distance and $\mathrm{pH}$ drive bacterial distribution in alkaline lake sediments across Tibetan Plateau. Environ Microbiol. 2012; 14(9):2457-2466.

5. Fernandez AB, Rasuk MC, Visscher PT, Contreras M, Novoa F, Poire DG, Patterson MM, Ventosa A, Farias ME. Microbial Diversity in Sediment Ecosystems (Evaporites Domes, Microbial Mats, and Crusts) of Hypersaline Laguna Tebenquiche, Salar de Atacama, Chile. Front Microbiol. 2016; 7.

6. Wang Y, Liu L, Chen H, Yang J. Spatiotemporal dynamics and determinants of planktonic bacterial and microeukaryotic communities in a Chinese subtropical river. Appl soil ecol. 2015; 99(21):92559266.

7. Van der Gucht K, Cottenie K, Muylaert K, Vloemans N, Cousin S, Declerck S, Jeppesen E, CondePorcuna J-M, Schwenk K, Zwart G. The power of species sorting: local factors drive bacterial 
community composition over a wide range of spatial scales. P Natl Acad Sci USA. 2007; 104(51):20404-20409.

8. Gong J, Shi F, Ma B, Dong J, Pachiadaki M, Zhang X, Edgcomb VP. Depth shapes a-and $\beta$-diversities of microbial eukaryotes in surficial sediments of coastal ecosystems. Environ Microbiol. 2015; 17(10):3722-3737.

9. Li S, Liu G, Miao F. The distribution and environmental background values of the heavy metals in sediment of the Bohai Sea. China Environ Sci. 1994; 14(5), 370-376.

10. Chen L, Zhang P, Shang W, Zhang H, Li Y, Zhang W, Zhang Z, Liu F. Enrichment culture of electroactive microorganisms with high magnetic susceptibility enhances the performance of microbial fuel cells. Bioelectrochemistry. 2018; 121:65-73.

11. Derkachev AN, Nikolaeva NA. Multivariate analysis of heavy mineral assemblages of sediments from the marginal seas of the Western Pacific. Dev Sedimentol. 2007; 58:439-464.

12. Zachara J, Gassman P, Smith S, Taylor D. Oxidation and adsorption of Co (II) EDTA2- complexes in subsurface materials with iron and manganese oxide grain coatings. Geochim Cosmochim Ac. 1995; 59(21):4449-4463.

13. Thamdrup B. Bacterial manganese and iron reduction in aquatic sediments. In: Advances in microbial ecology. Springer; 2000; 41-84.

14. Lin W, Bazylinski DA, Xiao T, Wu L, Pan Y. Life with compass: diversity and biogeography of magnetotactic bacteria. Environ Microbiol. 2014; 16(9):2646-2658.

15. Fuller SJ, McMillan DGG, Renz MB, Schmidt M, Burke IT, Stewart DI. Extracellular Electron TransportMediated Fe(III) Reduction by a Community of Alkaliphilic Bacteria That Use Flavins as Electron Shuttles. App/ Environ Microb. 2014; 80(1):128-137.

16. Zhang C, Qiao Q, Appel E, Huang B. Discriminating sources of anthropogenic heavy metals in urban street dusts using magnetic and chemical methods. J Geochem Explor. 2012; 119:60-75.

17. Amaral-Zettler LA, Zettler ER, Theroux SM, Palacios C, Aguilera A, Amils R. Microbial community structure across the tree of life in the extreme Rio Tinto. ISME J. 2011; 5(1):42.

18. Liu L, Yang J, Yu Z, Wilkinson DM. The biogeography of abundant and rare bacterioplankton in the lakes and reservoirs of China. ISME J. 2015; 9(9):2068.

19. Ragon M, Fontaine MC, Moreira D, LÓPEZ-GARCÍA P. Different biogeographic patterns of prokaryotes and microbial eukaryotes in epilithic biofilms. Mol ecol. 2012; 21(15):3852-3868.

20. Zhang H, Huang X, Huang L, Bao F, Xiong S, Wang K, Zhang D. Microeukaryotic biogeography in the typical subtropical coastal waters with multiple environmental gradients. Sci Total Environ. 2018; 635:618-628.

21. Mewafy FM, Atekwana EA, Werkema DD, Slater LD, Ntarlagiannis D, Revil A, Skold M, Delin GN. Magnetic susceptibility as a proxy for investigating microbially mediated iron reduction. Geophys Res Lett. 2011; 38. 
22. Weber KA, Achenbach LA, Coates JD. Microorganisms pumping iron: anaerobic microbial iron oxidation and reduction. Nat Rev Microbiol. 2006; 4(10):752-764.

23. Lovley DR, Holmes DE, Nevin KP. Dissimilatory Fe (III) and Mn (IV) reduction. Adv Microb Physiol. 2004; 49, 219-286.

24. Méndez-García C, Peláez Al, Mesa V, Sánchez J, Golyshina OV, Ferrer M. Microbial diversity and metabolic networks in acid mine drainage habitats. Front Microbiol. 2015; 6:475.

25. Lozupone CA, Knight R. Global patterns in bacterial diversity. P Natl Acad Sci USA. 2007; 104(27):11436-11440.

26. Nemergut DR, Costello EK, Hamady M, Lozupone C, Jiang L, Schmidt SK, Fierer N, Townsend AR, Cleveland CC, Stanish L. Global patterns in the biogeography of bacterial taxa. Environ Microbiol. 2011; 13(1):135-144.

27. Campbell BJ, Kirchman DL. Bacterial diversity, community structure and potential growth rates along an estuarine salinity gradient. ISME J. 2013; 7(1):210.

28. Herlemann DP, Labrenz M, Jürgens K, Bertilsson S, Waniek JJ, Andersson AF. Transitions in bacterial communities along the $2000 \mathrm{~km}$ salinity gradient of the Baltic Sea. ISME J. 2011; 5(10):1571.

29. Oren A. The bioenergetic basis for the decrease in metabolic diversity at increasing salt concentrations: implications for the functioning of salt lake ecosystems. In: Saline Lakes. Springer; $2001 ; 61-72$.

30. Oren A. Thermodynamic limits to microbial life at high salt concentrations. Environ Microbiol. 2011; 13(8):1908-1923.

31. Polymenakou PN, Christakis CA, Mandalakis M, Oulas A. Pyrosequencing analysis of microbial communities reveals dominant cosmopolitan phylotypes in deep-sea sediments of the eastern Mediterranean Sea. Res. Microbiol. 2015;166(5):448-457.

32. Feng $\mathrm{Y}$, Grogan P, Caporaso JG, Zhang H, Lin X, Knight R, Chu H. pH is a good predictor of the distribution of anoxygenic purple phototrophic bacteria in Arctic soils. Soil Biol Biochem. 2014; 74:193-200.

33. Landa M, Cottrell M, Kirchman D, Kaiser K, Medeiros P, Tremblay L, Batailler N, Caparros J, Catala P, Escoubeyrou K. Phylogenetic and structural response of heterotrophic bacteria to dissolved organic matter of different chemical composition in a continuous culture study. Environ Microbiol. 2014;16(6):1668-1681.

34. Teeling H, Fuchs BM, Becher D, Klockow C, Gardebrecht A, Bennke CM, Kassabgy M, Huang S, Mann AJ, Waldmann J. Substrate-controlled succession of marine bacterioplankton populations induced by a phytoplankton bloom. Science. 2012; 336(6081):608-611.

35. Miyatake T, Moerdijk-Poortvliet TC, Stal LJ, Boschker HT. Tracing carbon flow from microphytobenthos to major bacterial groups in an intertidal marine sediment by using an in situ $13 \mathrm{C}$ pulse-chase method. Limnol. Oceanogr. 2014; 59(4):1275-1287.

36. McCauley A, Jones C, Olson-Rutz K. Soil pH and organic matter. Nutr Manage Module. No. 8. In.: Bozeman: Montana State University; 2017. 
37. Bauer M, Kube M, Teeling H, Richter M, Lombardot T, Allers E, Würdemann CA, Quast $C$, Kuhl $H$, Knaust $F$. Whole genome analysis of the marine Bacteroidetes 'Gramella forsetii'reveals adaptations to degradation of polymeric organic matter. Environ Microbiol. 2006; 8(12):2201-2213.

38. Brown MV, Ostrowski M, Grzymski JJ, Lauro FM. A trait based perspective on the biogeography of common and abundant marine bacterioplankton clades. Mar. Genom. 2014; 15:17-28.

39. Xia X, Guo W, Liu H. Dynamics of the bacterial and archaeal communities in the Northern South China Sea revealed by 454 pyrosequencing of the 16S rRNA gene. Deep Sea Res.Part II: Topical Studies in Oceanography 2015; 117:97-107.

40. Zhang SY, Zheng XW, Zhang WZ, Song QX, Zheng Z, Luo XZ. The Effect of Bioavailable Sedimentary Iron on the Growth of Cyanobacteria in Eutrophic Lakes. Water Air Soil Poll. 2018; 229(10).

41. Dang TC, Fujii M, Rose AL, Bligh M, Waite TD. Characteristics of the Freshwater Cyanobacterium Microcystis aeruginosa Grown in Iron-Limited Continuous Culture. App/ Environ Microb. 2012; 78(5):1574-1583.

42. Lovley DR. Dissimilatory Fe (III) and Mn (IV) reduction. Mol Biol R. 1991; 55(2):259-287.

43. Porsch K, Rijal ML, Borch T, Troyer LD, Behrens S, Wehland F, Appel E, Kappler A. Impact of organic carbon and iron bioavailability on the magnetic susceptibility of soils. Geochim Cosmochim Ac. 2014; 128:44-57.

44. Chen Z, Wang YP, Jiang XL, Fu D, Xia D, Wang HT, Dong GW, Li QBA. Dual roles of AQDS as electron shuttles for microbes and dissolved organic matter involved in arsenic and iron mobilization in the arsenic-rich sediment. Sci Total Environ. 2017; 574:1684-1694.

45. Yun SH, Hwang TS, Park DH. Metabolic characterization of lactic acid bacterium Lactococcus garvieae sk11, capable of reducing ferric iron, nitrate, and fumarate. J Microbiol Biotechn. 2007; 17(2):218-225.

46. Lin XQ, Li ZL, Liang B, Zhai HL, Cai WW, Nan J, Wang AJ. Accelerated microbial reductive dechlorination of 2,4,6-trichlorophenol by weak electrical stimulation. Water Res. 2019; 162:236-245.

47. Xu Y, He Y, Feng XL, Liang LY, Xu JM, Brookes PC, Wu JJ. Enhanced abiotic and biotic contributions to dechlorination of pentachlorophenol during $\mathrm{Fe}$ (III) reduction by an iron-reducing bacterium Clostridium beijerinckii Z. Sci Total Environ. 2014; 473:215-223.

48. Kormas KA, Tivey MK, Von Damm K, Teske A. Bacterial and archaeal phylotypes associated with distinct mineralogical layers of a white smoker spire from a deep-sea hydrothermal vent site (9 degrees N, East Pacific Rise). Environ Microbiol. 2006; 8(5):909-920.

49. Shao KQ, Zhang L, Wang YP, Yao X, Tang XM, Qin BQ, Gao G. The responses of the taxa composition of particle-attached bacterial community to the decomposition of Microcystis blooms. Sci Total Environ. 2014; 488:236-242.

50. Sugita $\mathrm{H}$, Mizuki $\mathrm{H}$, Itoi S. Diversity of siderophore-producing bacteria isolated from the intestinal tracts of fish along the Japanese coast. Aquac Res. 2012; 43(4):481-488.

51. Saha M, Sarkar S, Sarkar B, Sharma BK, Bhattacharjee S, Tribedi P. Microbial siderophores and their potential applications: a review. Environ Sci Pollut. R2016; 23(5):3984-3999. 
52. Hanson CA, Fuhrman JA, Horner-Devine MC, Martiny JB. Beyond biogeographic patterns: processes shaping the microbial landscape. Nat Rev Microbiol. 2012; 10(7):497.

53. Martiny JBH, Bohannan BJ, Brown JH, Colwell RK, Fuhrman JA, Green JL, Horner-Devine MC, Kane $\mathrm{M}$, Krumins JA, Kuske CR. Microbial biogeography: putting microorganisms on the map. Nat Rev Microbiol. 2006; 4(2):102.

54. Soininen J, Korhonen JJ, Luoto M. Stochastic species distributions are driven by organism size. Ecology. 2013; 94(3):660-670.

55. Logares R, Audic S, Bass D, Bittner L, Boutte C, Christen R, Claverie J-M, Decelle J, Dolan JR, Dunthorn M. Patterns of rare and abundant marine microbial eukaryotes. Curr Biol. 2014; 24(8):813-821.

56. Astorga A, Oksanen J, Luoto M, Soininen J, Virtanen R, Muotka T. Distance decay of similarity in freshwater communities: do macro-and microorganisms follow the same rules? Global Ecol. Biogeogr. 2012; 21(3):365-375.

57. Wang M, Chen L, Li Y, Chen L, Liu Z, Wang X, Yan P, Qin S. Responses of soil microbial communities to a short-term application of seaweed fertilizer revealed by deep amplicon sequencing. Appl Microbiol Biot. 2018; 125:288-296.

58. Caporaso JG, Kuczynski J, Stombaugh J, Bittinger K, Bushman FD, Costello EK, Fierer N, Pena AG, Goodrich JK, Gordon JI. QIIME allows analysis of high-throughput community sequencing data. Nat methods. 2010; 7(5):335.

59. Hill TC, Walsh KA, Harris JA, Moffett BF. Using ecological diversity measures with bacterial communities. FEMS Microbiol Ecol. 2003; 43(1):1-11.

60. Chao A, Bunge J. Estimating the number of species in a stochastic abundance model. Biometrics. 2002; 58(3):531-539.

61. Diniz-Filho JAF, Soares TN, Lima JS, Dobrovolski R, Landeiro VL, Telles MPdC, Rangel TF, Bini LM. Mantel test in population genetics. Genet mol Biol. 2013; 36(4):475-485.

62. Bray JR, Curtis JT. An ordination of the upland forest communities of southern Wisconsin. Ecol Monogr. 1957; 27(4):325-349.

63. Goslee SC, Urban DL. The ecodist package for dissimilarity-based analysis of ecological data. J Stat Softw. 2007; 22(7):1-19.

64. Borcard D, Legendre P, Drapeau P. Partialling out the spatial component of ecological variation. Ecology. 1992; 73(3):1045-1055.

65. Borcard D, Legendre P. All-scale spatial analysis of ecological data by means of principal coordinates of neighbour matrices. Ecol Model. 2002; 153(1-2):51-68.

66. Blanchet FG, Legendre P, Borcard D. Forward selection of explanatory variables. Ecology. 2008; 89(9):2623-2632.

\section{Tables}


Table 1 Relationship between chemical properties and bacterial a-diversity or $\beta$-diversity of microbial communities (Bray-Curtis dissimilarity) across samples of A sediment ${ }^{a}$.

\begin{tabular}{|c|c|c|c|c|c|c|c|c|c|c|}
\hline & \multicolumn{2}{|c|}{ Chao 1 index } & \multicolumn{2}{|c|}{$\begin{array}{l}\text { Observed-OTU } \\
\text { richness (S) }\end{array}$} & \multicolumn{2}{|c|}{$\begin{array}{l}\text { Shannon } \\
\text { Wiener index } \\
\left(\mathrm{H}^{\prime}\right)\end{array}$} & \multicolumn{4}{|l|}{ OTU } \\
\hline & $r$ & $P$ & $r$ & $P$ & $r$ & $P$ & $r$ & $P$ & $r$ geo $^{e}$ & $P$ geo \\
\hline Salinity & 0.254 & $\begin{array}{l}0.012 \\
c\end{array}$ & 0.303 & $\begin{array}{l}0.005 \\
c\end{array}$ & 0.234 & $\begin{array}{l}0.017 \\
c\end{array}$ & 0.680 & $\begin{array}{l}0.001 \\
d\end{array}$ & 0.694 & 0.001 \\
\hline $\mathrm{pH}$ & 0.074 & 0.199 & 0.083 & 0.171 & 0.056 & 0.266 & 0.462 & ${ }_{d}^{0.001}$ & 0.443 & 0.001 \\
\hline $\mathrm{DO}^{b}$ & 0.188 & $\begin{array}{l}0.034 \\
c\end{array}$ & 0.246 & $\begin{array}{l}0.014 \\
c\end{array}$ & 0.149 & 0.063 & 0.528 & ${ }_{d}^{0.001}$ & 0.548 & 0.001 \\
\hline $\mathrm{Fe}$ & 0.109 & 0.115 & 0.157 & 0.055 & 0.236 & $\begin{array}{l}0.016 \\
c\end{array}$ & 0.131 & 0.072 & 0.126 & 0.080 \\
\hline Xlf $^{b}$ & 0.064 & 0.233 & 0.072 & 0.206 & 0.048 & 0.304 & 0.388 & $l_{d}^{0.006}$ & 0.381 & 0.009 \\
\hline TOC & 0.031 & 0.409 & 0.016 & 0.559 & 0.045 & 0.320 & -0.031 & 0.061 & 0.003 & 0.481 \\
\hline TN & 0.090 & 0.154 & 0.066 & 0.226 & 0.053 & 0.278 & -0.121 & 0.772 & -0.158 & 0.898 \\
\hline
\end{tabular}

${ }^{a}$ Codes in A sediment refer to the points shown in supplementary Table S2.

${ }^{b} \mathrm{Xlf}$, low-(0.47 kHz) frequency susceptibility; DO, dissolved oxygen.

${ }^{c}$ Correlation $(r)$ and $P$-value in bold indicates significant difference $(P<0.05)$ tested by correlation analysis.

${ }^{d}$ Pearson's product-moment correlation $(r)$ and $P$-value in bold indicates significant difference $(P<0.05)$ tested by Mantel.

${ }^{e}$ Correlation coefficients between the pairwise distance of environmental variables and $\beta$-diversity of microeukaryotic community when pairwise geographic distance was controlled in the partial Mantel test.

\section{Table 2}

Results from the PERMANOVA (Adonis) and multiple regressions on distance matrix (MRM) model based on Bray-Curtis dissimilarity with 9999 permutations. 


\begin{tabular}{|lllll|}
\hline Variables & $\mathrm{R}^{2}(\mathrm{MRM})$ & $P$ & $\mathrm{R}^{2}$ (adonis) & $P$ \\
\hline Salinity $^{a}$ & 0.469 & $<0.001$ & 0.265 & $<0.001$ \\
\hline pH & 0.204 & $<0.001$ & 0.170 & $<0.001$ \\
\hline DO & 0.294 & $<0.001$ & 0.285 & $<0.001$ \\
\hline Fe & 0.022 & 0.057 & 0.066 & 0.240 \\
\hline Xlf & 0.140 & $\mathbf{0 . 0 0 4}$ & 0.138 & $\mathbf{0 . 0 1 7}$ \\
\hline TOC & $<0.001$ & 0.931 & 0.104 & 0.060 \\
\hline TN & 0.017 & 0.387 & 0.054 & 0.455 \\
\hline
\end{tabular}

${ }^{a} P$-value in bold indicates significant difference $(P<0.05)$.

Table 3 Correlation analysis based on Spearman's rank correlation coefficient between relative abundances of bacterial genera and geographical distance to the center of magnetite from 19 locations. 


\begin{tabular}{|lll|}
\hline Genera & $r$ & $P$ \\
\hline Lactococcus & $\mathbf{0 . 2 2 0}$ & $\mathbf{0 . 0 4 3}^{a}$ \\
Lutimonas & 0.022 & 0.547 \\
\hline Caulobacter & $\mathbf{0 . 2 1 7}$ & $\mathbf{0 . 0 4 5}^{a}$ \\
\hline Desulfococcus & 0.074 & 0.260 \\
\hline Gillisia & $\mathbf{0 . 3 6 6}$ & $\mathbf{0 . 0 0 6 ^ { a }}$ \\
\hline Vibrio & 0.083 & 0.231 \\
\hline Bacillus & 0.044 & 0.391 \\
\hline Photobacterium & 0.108 & 0.170 \\
\hline Muricola & 0.087 & 0.221 \\
\hline Clostridium & $\mathbf{0 . 3 7 2}$ & $\mathbf{0 . 0 0 6}{ }^{a}$ \\
\hline Sphingomonas & $\mathbf{0 . 2 5 5}$ & $\mathbf{0 . 0 2 7}{ }^{a}$ \\
\hline Planctomyces & 0.045 & 0.382 \\
\hline Arthrobacter & 0.151 & 0.101 \\
\hline Amphritea & 0.063 & 0.300 \\
\hline Nitrospira & 0.038 & 0.424 \\
\hline
\end{tabular}

${ }^{a}$ Correlation $(r)$ and $P$-value in bold indicates significant difference $(P<0.05)$ tested by correlation analysis.

\section{Table 4}

Mantel tests showing the Spearman's rank correlations between ENV and geodistance. 


\begin{tabular}{|lll|}
\hline Variables & $\rho$ & $\mathrm{P}$ \\
\hline Salinity & -0.026 & 0.553 \\
\hline Fe & 0.210 & $\mathbf{0 . 0 2 0}^{a}$ \\
\hline Xlf & -0.016 & 0.521 \\
\hline TOC (\%) & -0.083 & 0.845 \\
\hline TN & 0.112 & 0.128 \\
\hline pH & 0.161 & 0.064 \\
\hline DO & -0.051 & 0.721 \\
\hline
\end{tabular}

${ }^{a} P$-value in bold indicates significant difference $(P<0.05)$ tested by Spearman's rank correlation analysis.

Figures 


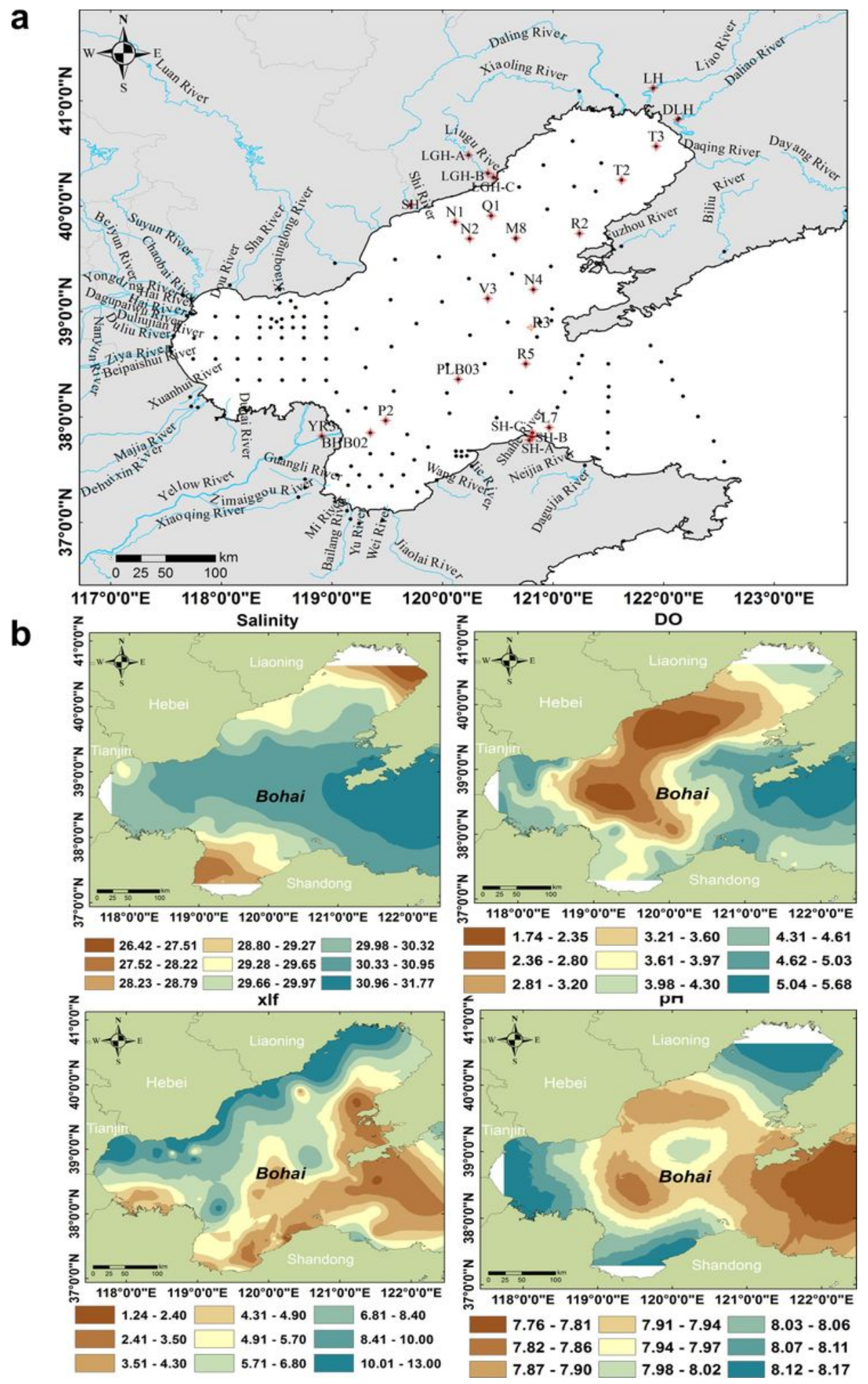

\section{Figure 1}

a A map of the study area . Black dots denote sampling sites. The letters denote site names. Red " $\oplus$ " represent sites chosen for further study of microbial community structure. Daliao River sites (DLH-A, DLHB, DLH-C), Liao River (LH), Liugu River sites (LGH-A, LGH-B, LGH-C), Shi River (SH), Yellow River (YR), and the Sha River (SH-A, SH-B, SH-C). Q1, M8, T3, T2, N1, N2, L7, PLB03, V3, N4, R2, R3, and R5 indicate sediment sample sites located in the Bohai Sea. b Maps showing environmental characteristics the 
salinity, dissolved oxygen (DO), the low-frequency magnetic susceptibility (Xlf) of the sediment, and pH of the overlying water across the Bohai Sea. The maps were constructed using ArcGIS 10.0 software.

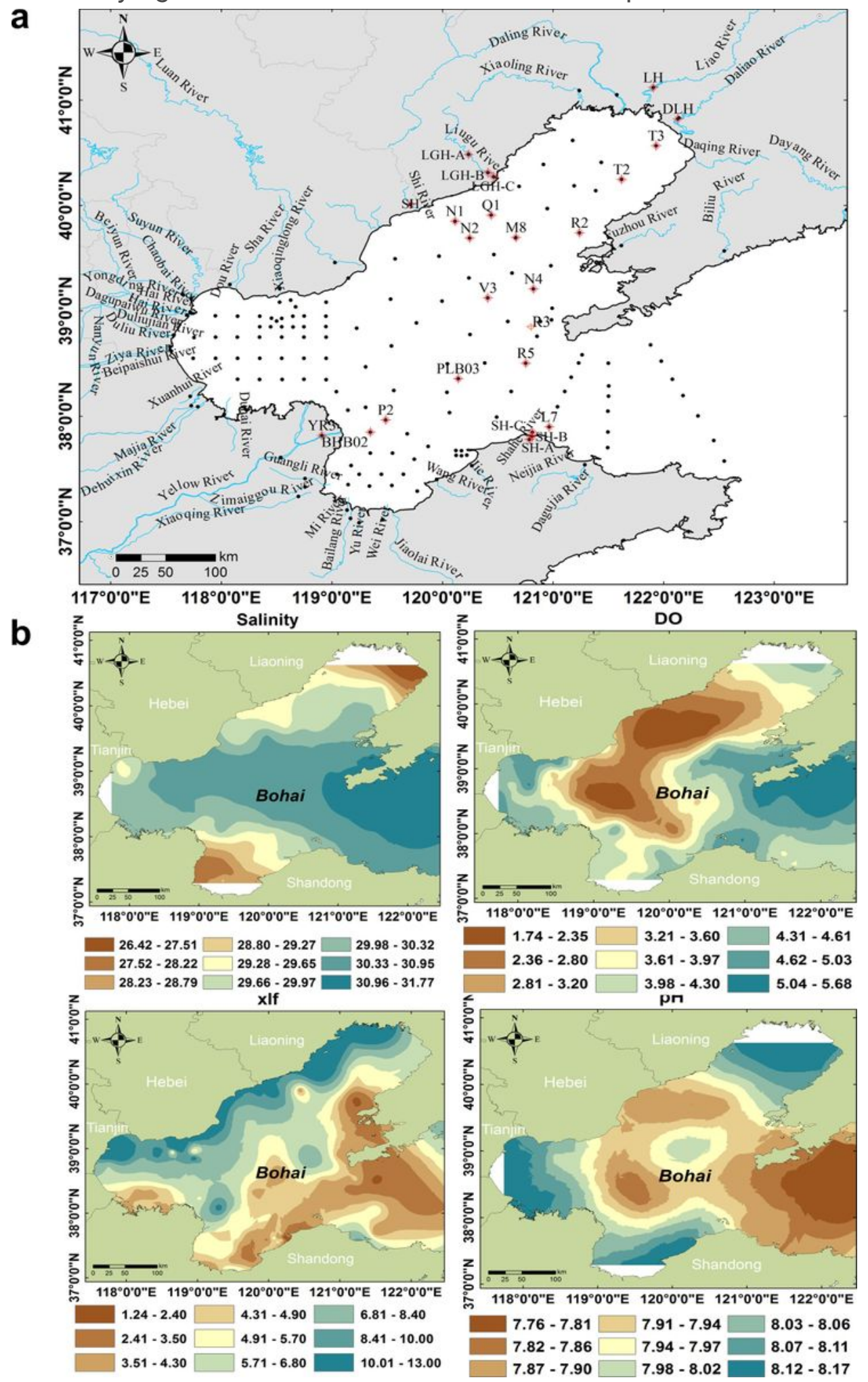

\section{Figure 1}

a A map of the study area . Black dots denote sampling sites. The letters denote site names. Red " $\oplus$ " represent sites chosen for further study of microbial community structure. Daliao River sites (DLH-A, DLHB, DLH-C), Liao River (LH), Liugu River sites (LGH-A, LGH-B, LGH-C), Shi River (SH), Yellow River (YR), and 
the Sha River (SH-A, SH-B, SH-C). Q1, M8, T3, T2, N1, N2, L7, PLB03, V3, N4, R2, R3, and R5 indicate sediment sample sites located in the Bohai Sea. b Maps showing environmental characteristics the salinity, dissolved oxygen (DO), the low-frequency magnetic susceptibility (Xlf) of the sediment, and pH of the overlying water across the Bohai Sea. The maps were constructed using ArcGIS 10.0 software.

a
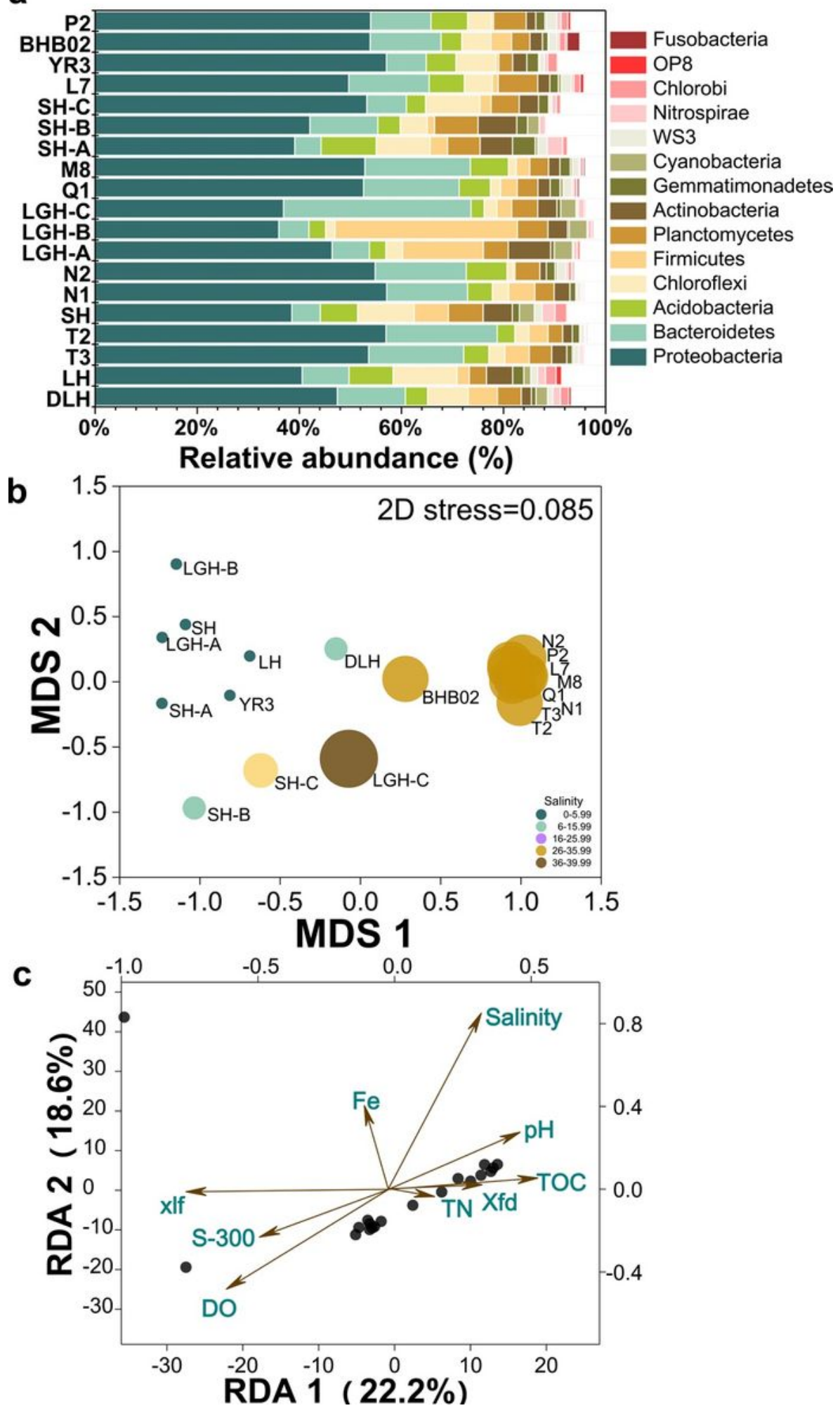

Figure 2 
a Microbial community composition in the study area at the phylum level. b an NMDS plot based on an OTU-based Bray-Curtis distance metric derived from the freshwater and marine sediment samples. $c$ an RDA plot of the bacterial communities and the main environmental characteristics.

a
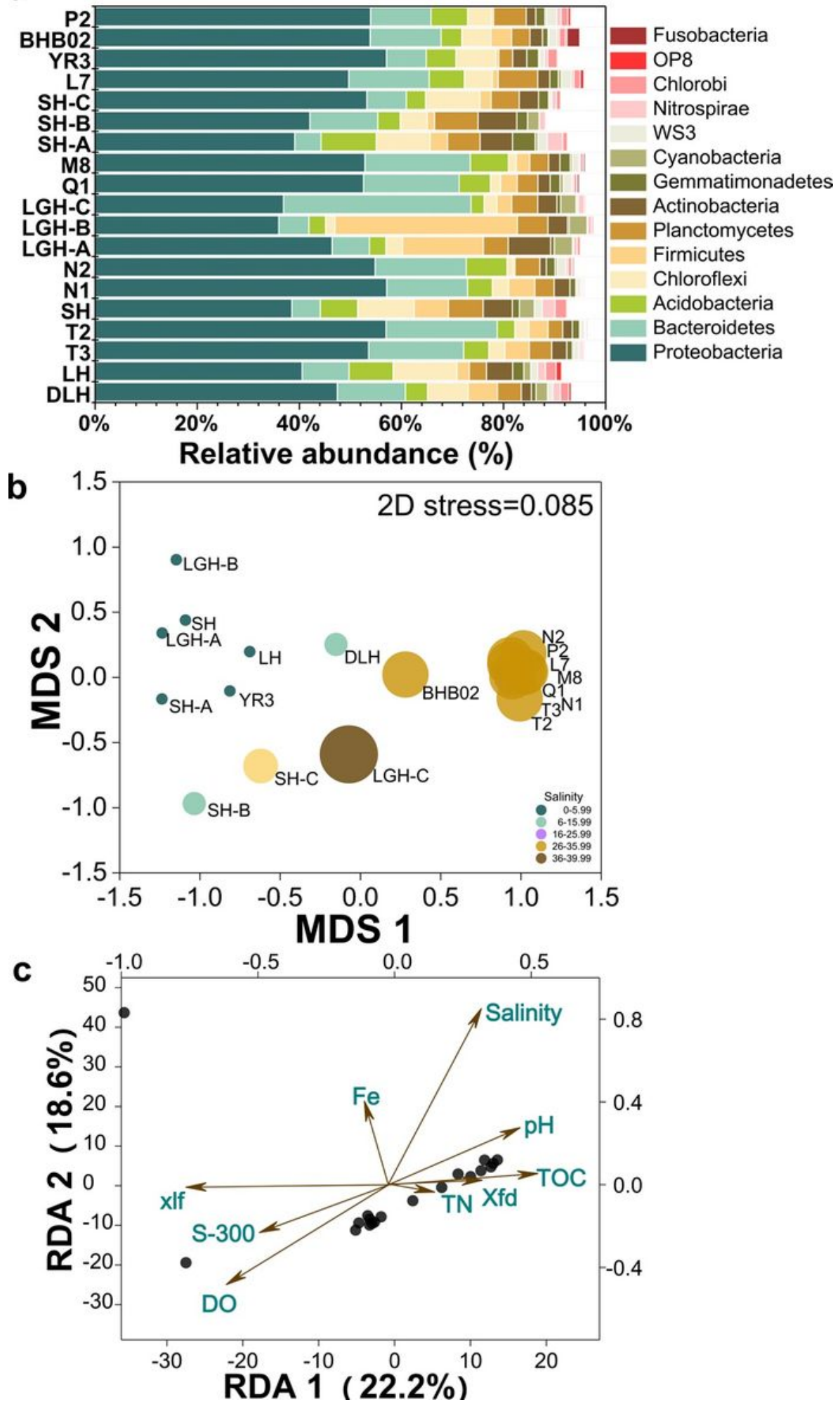

Figure 2

a Microbial community composition in the study area at the phylum level. $b$ an NMDS plot based on an OTU-based Bray-Curtis distance metric derived from the freshwater and marine sediment samples. $c$ an 
RDA plot of the bacterial communities and the main environmental characteristics.
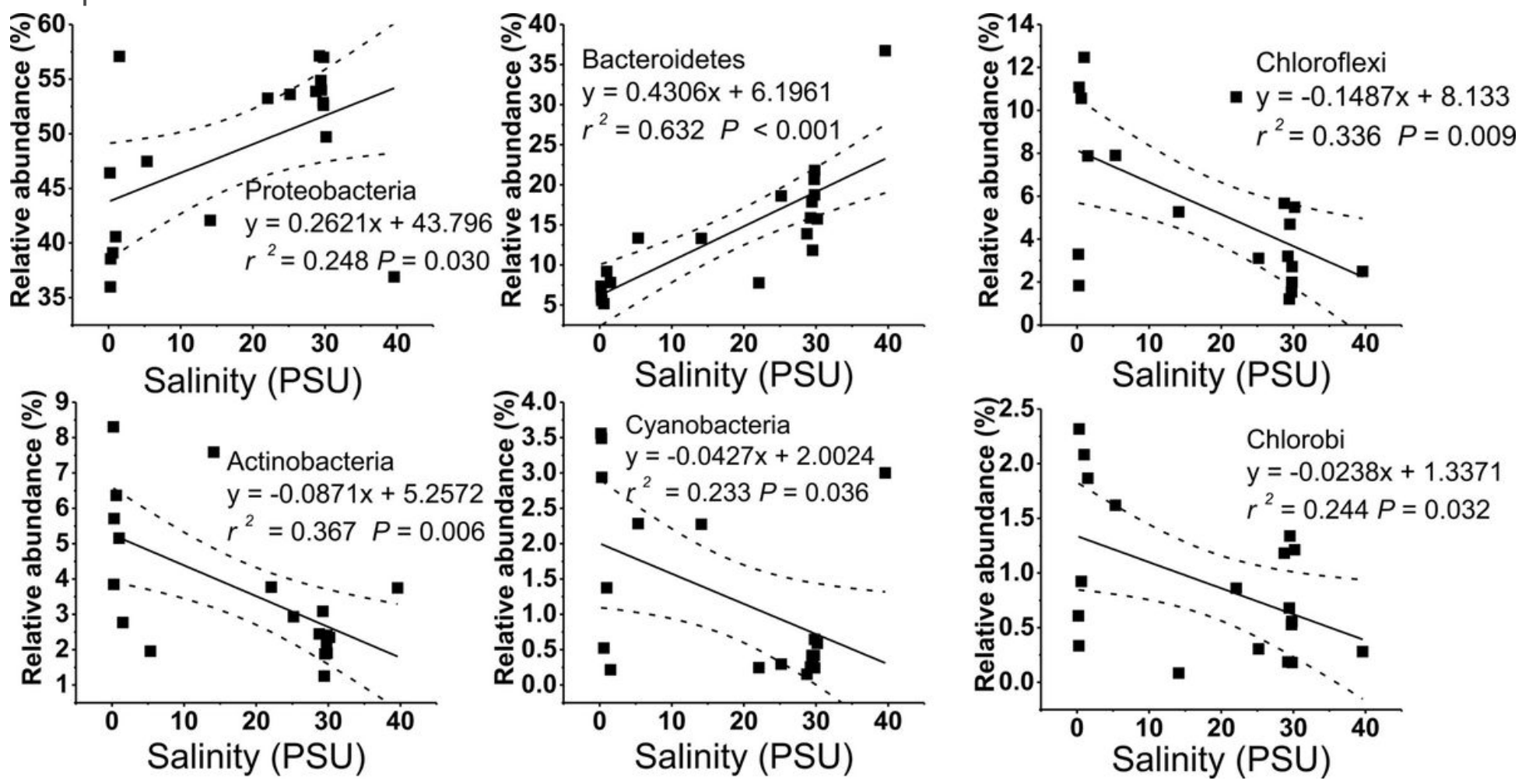

Figure 3

The relative abundances of the dominant bacterial phyla at each elevation in relation to sediment salinity. The strength of each relationship given is based on the linear regression equation. Solid lines show regression lines, dashed lines show $95 \%$ confidence limits on regression lines.
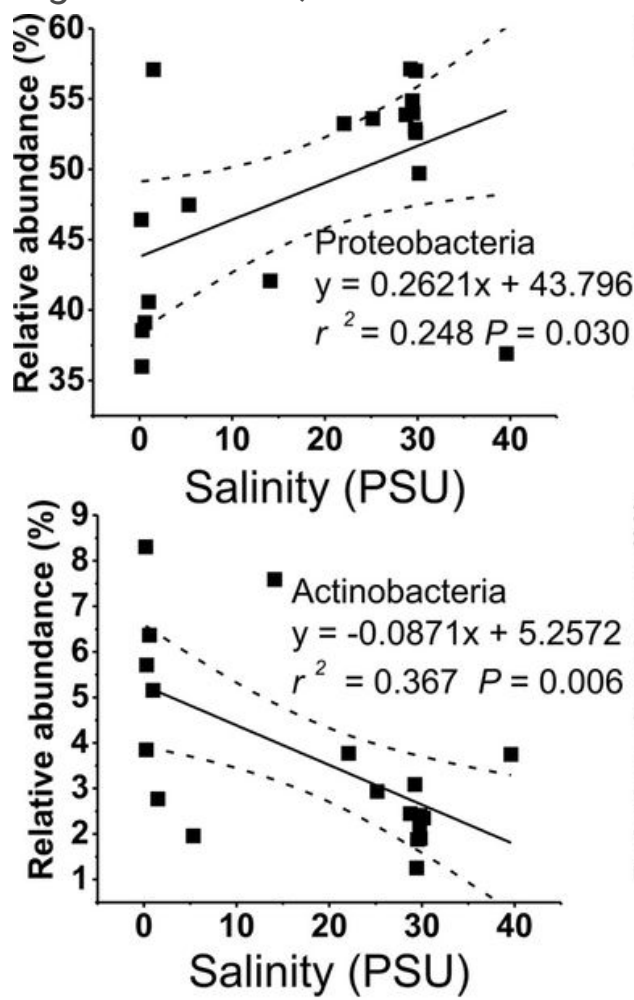
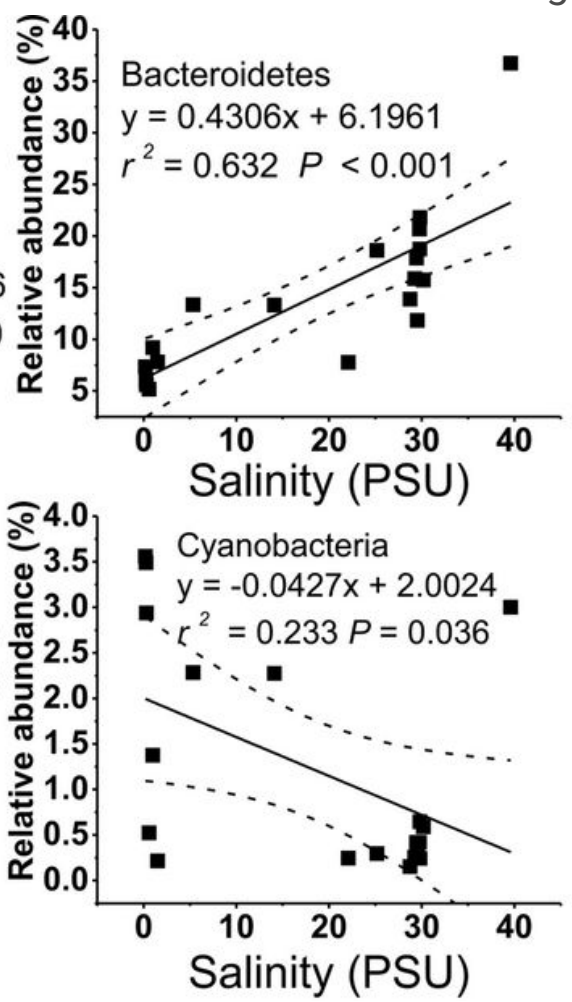
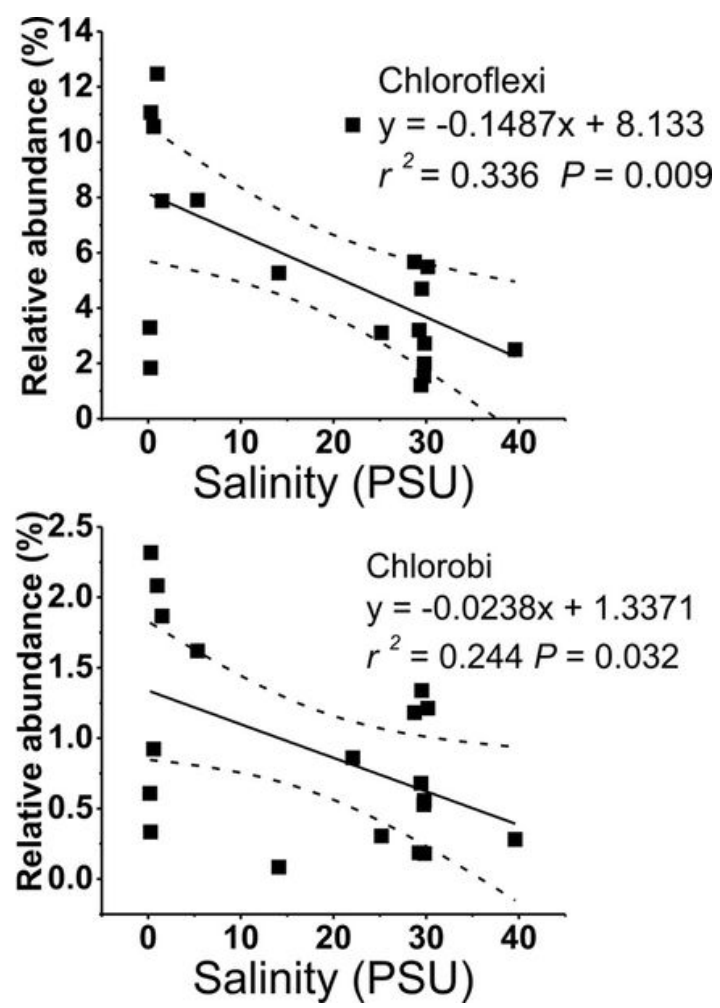

Figure 3 
The relative abundances of the dominant bacterial phyla at each elevation in relation to sediment salinity. The strength of each relationship given is based on the linear regression equation. Solid lines show regression lines, dashed lines show 95\% confidence limits on regression lines.
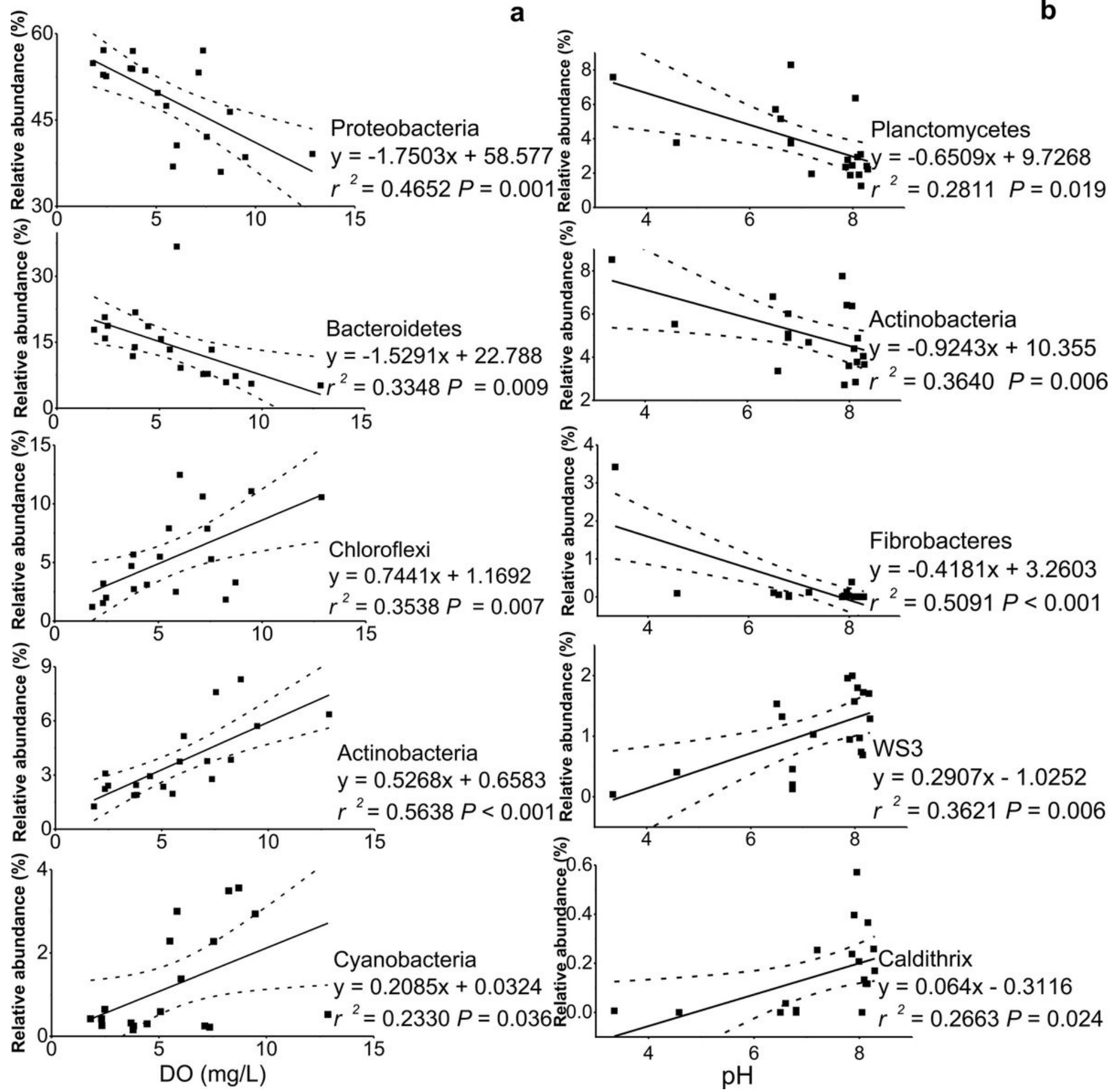

Figure 4

The relative abundances of the dominant bacterial phyla at each elevation in relation to sediment a DO and $\mathrm{b} \mathrm{pH}$. The strength of each relationship given is based on the linear regression equation. Solid lines show regression lines, dashed lines show 95\% confidence limits on regression lines. 

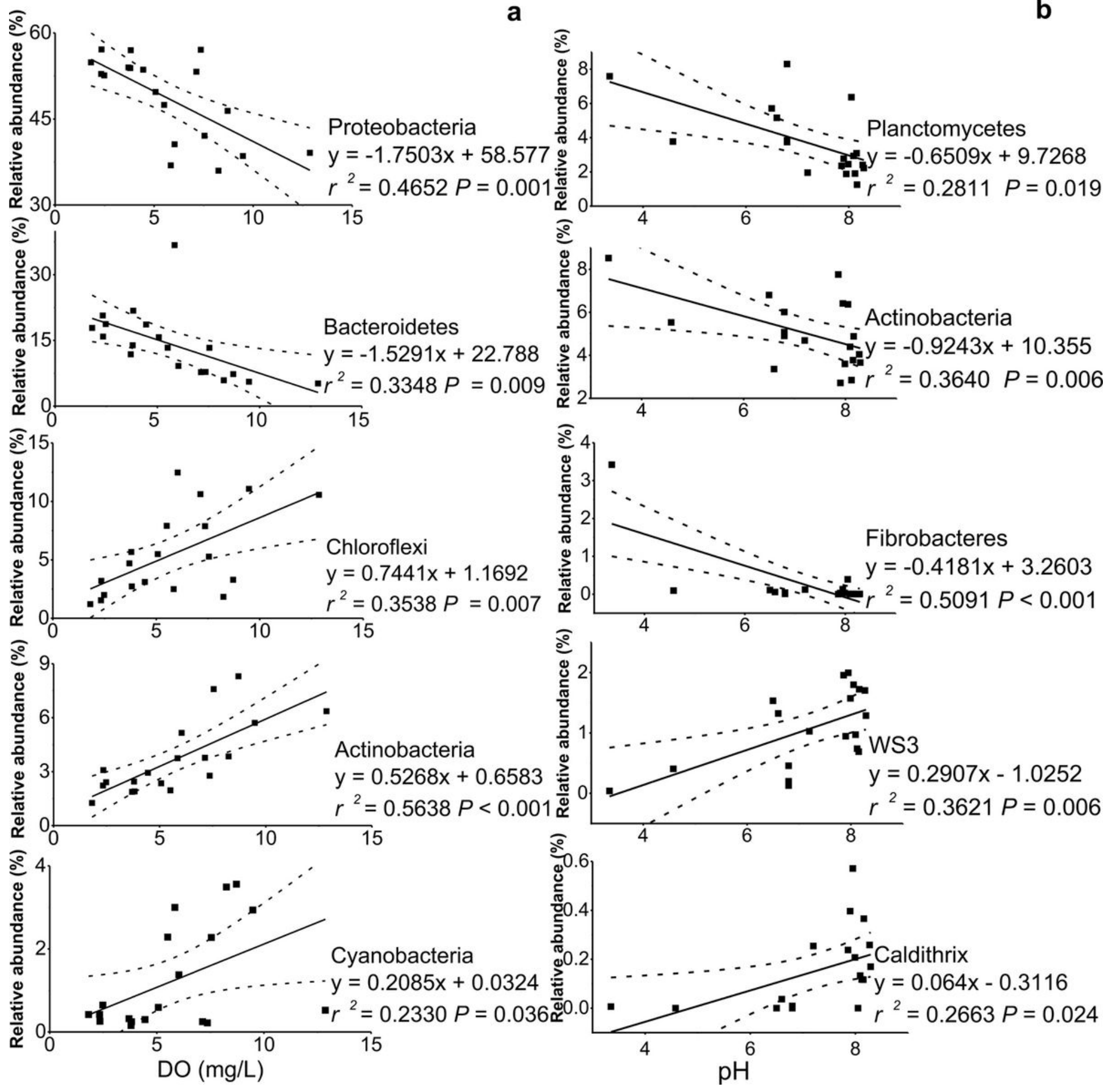

Figure 4

The relative abundances of the dominant bacterial phyla at each elevation in relation to sediment a DO and $\mathrm{b} \mathrm{pH}$. The strength of each relationship given is based on the linear regression equation. Solid lines show regression lines, dashed lines show $95 \%$ confidence limits on regression lines. 

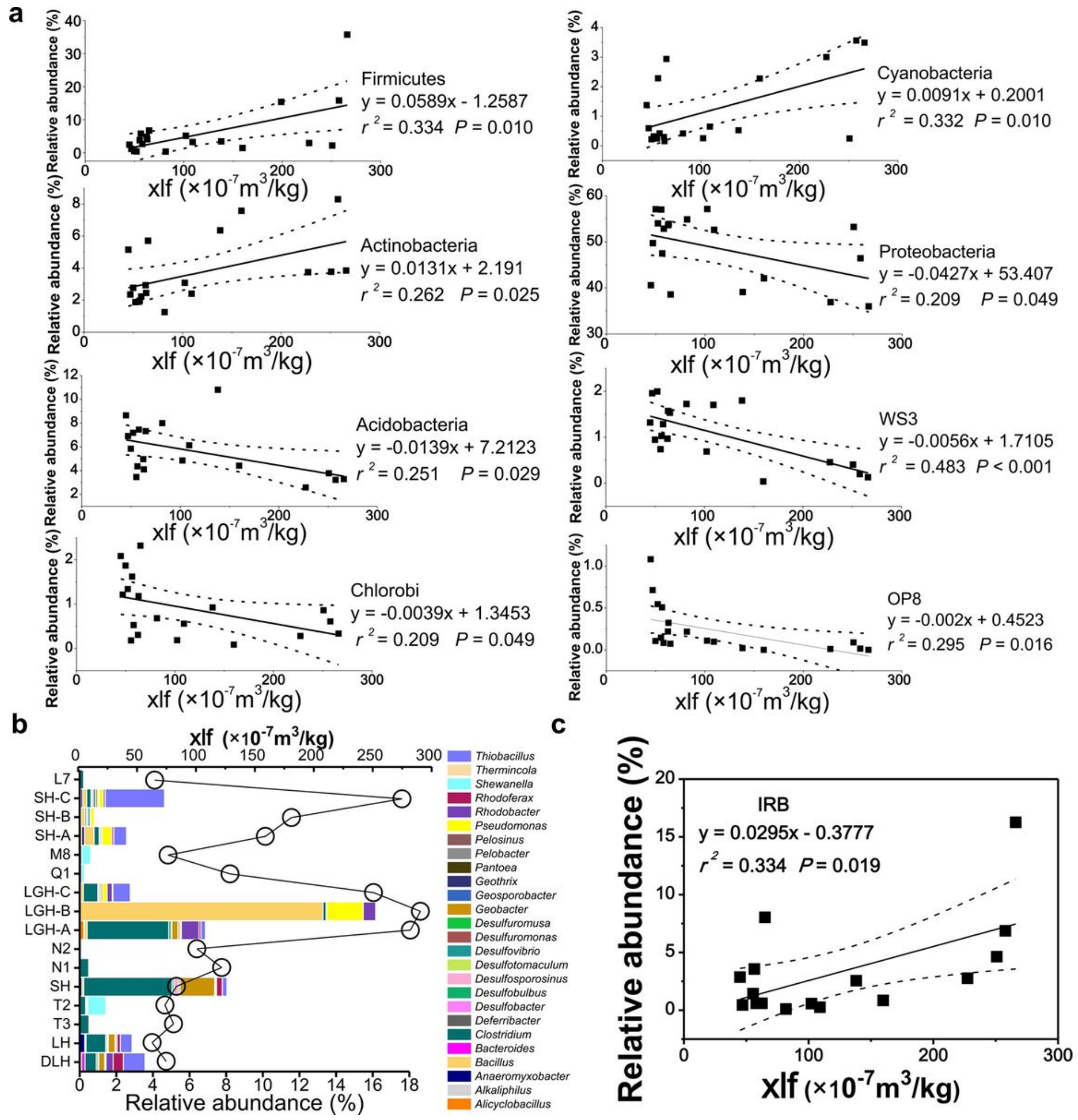

Figure 5

a The relative abundances of the dominant bacterial phyla at each elevation in relation to sediment $\chi$ lf. The strength of each relationship given is based on the linear regression equation. Solid lines show regression lines, dashed lines show 95\% confidence limits on regression lines. b Relationship between genera of DIRB and magnetic characters. low-frequency magnetic susceptibility ( $\chi$ lf) of sediments in Table S1. c Regression analysis in between the relative abundance of identified DIRB genera and Xlf . 

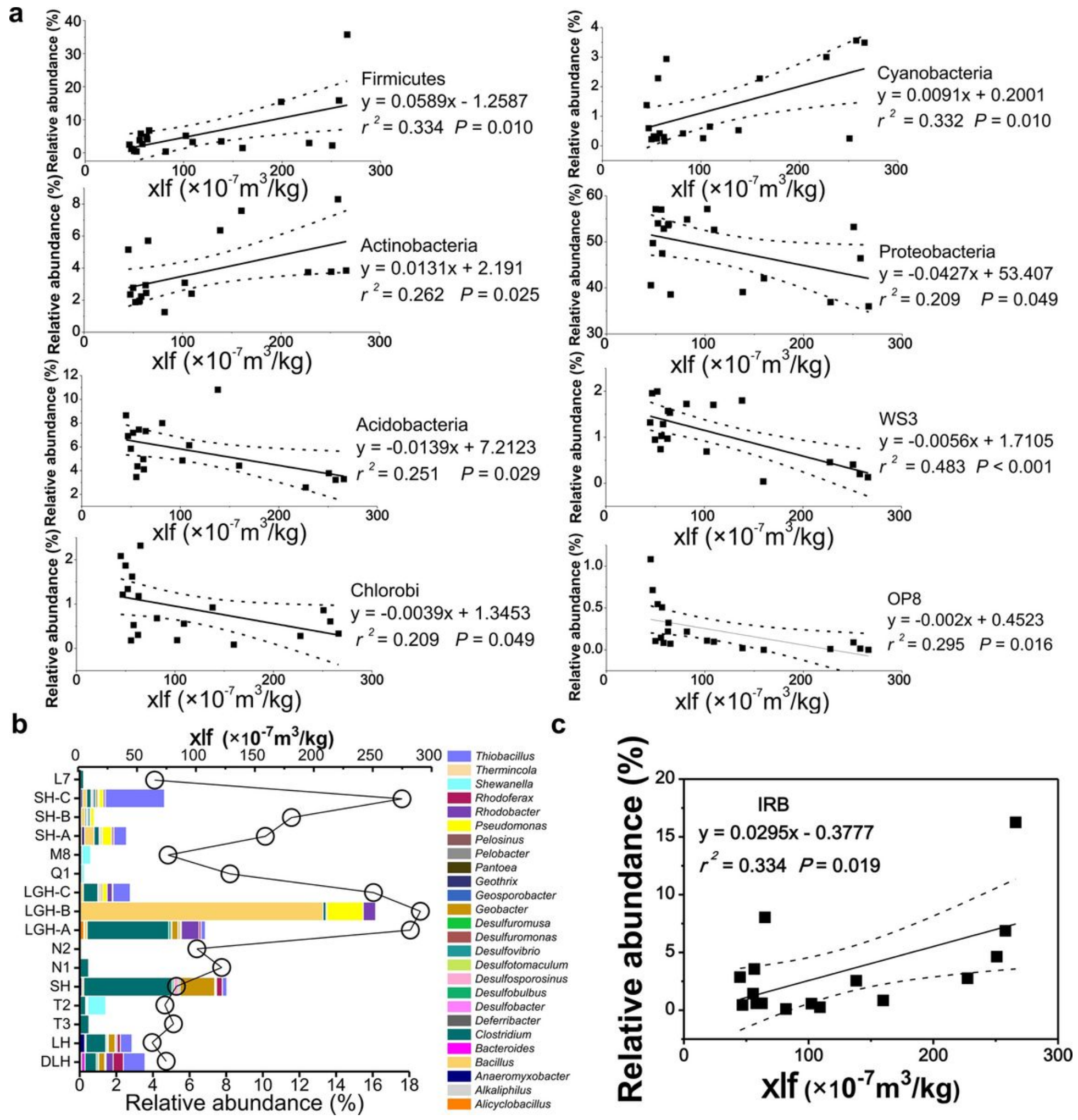

Figure 5

a The relative abundances of the dominant bacterial phyla at each elevation in relation to sediment $\chi$ lf. The strength of each relationship given is based on the linear regression equation. Solid lines show regression lines, dashed lines show 95\% confidence limits on regression lines. b Relationship between genera of DIRB and magnetic characters. low-frequency magnetic susceptibility ( $\chi$ lf) of sediments in Table S1. c Regression analysis in between the relative abundance of identified DIRB genera and Xlf . 


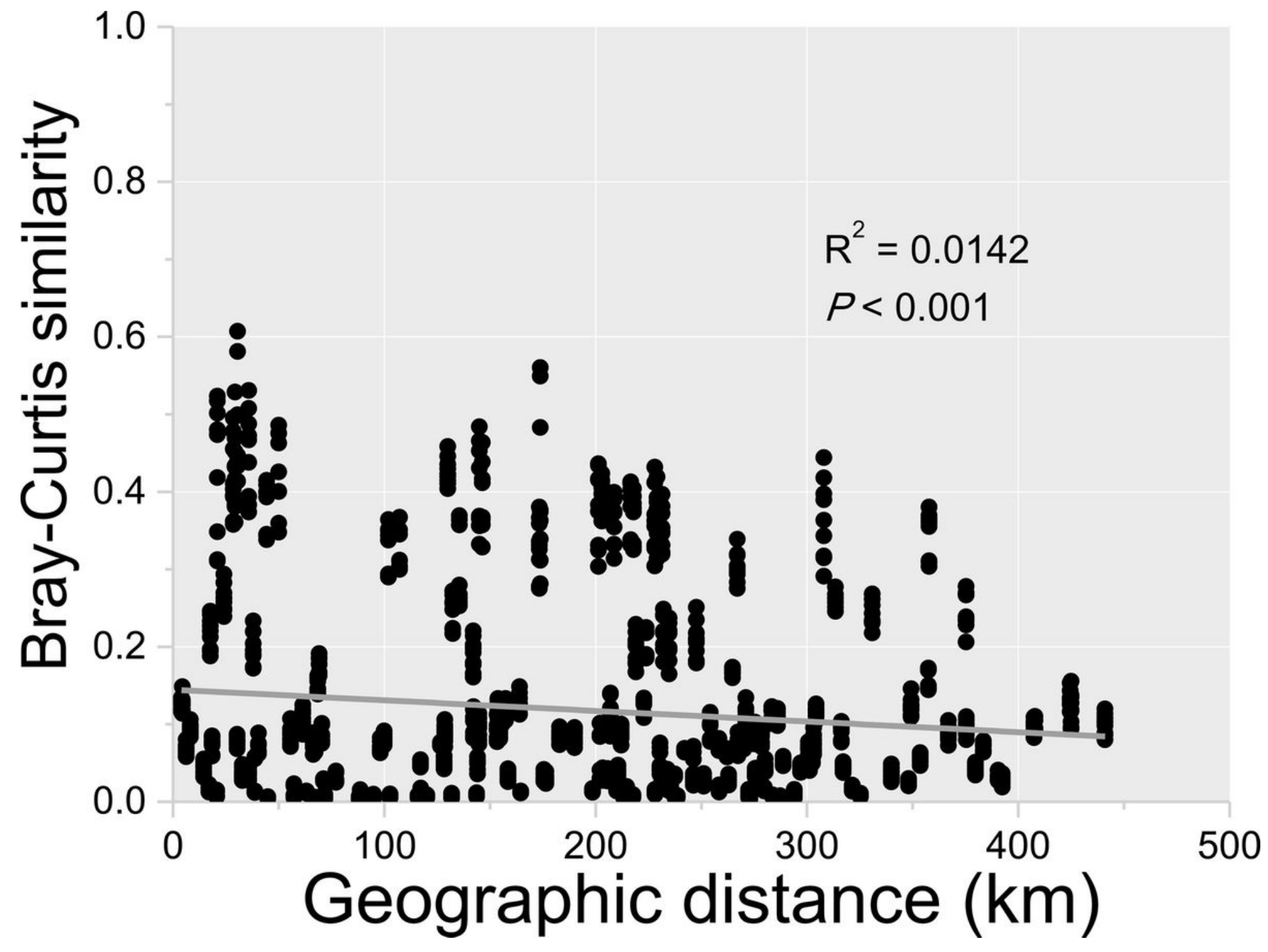

Figure 6

Relationship between the Bray-Curtis similarity of the microbial community and geographic distance between sampling stations. The solid red line indicates the fit between geographic distance and BrayCurtis similarity. 


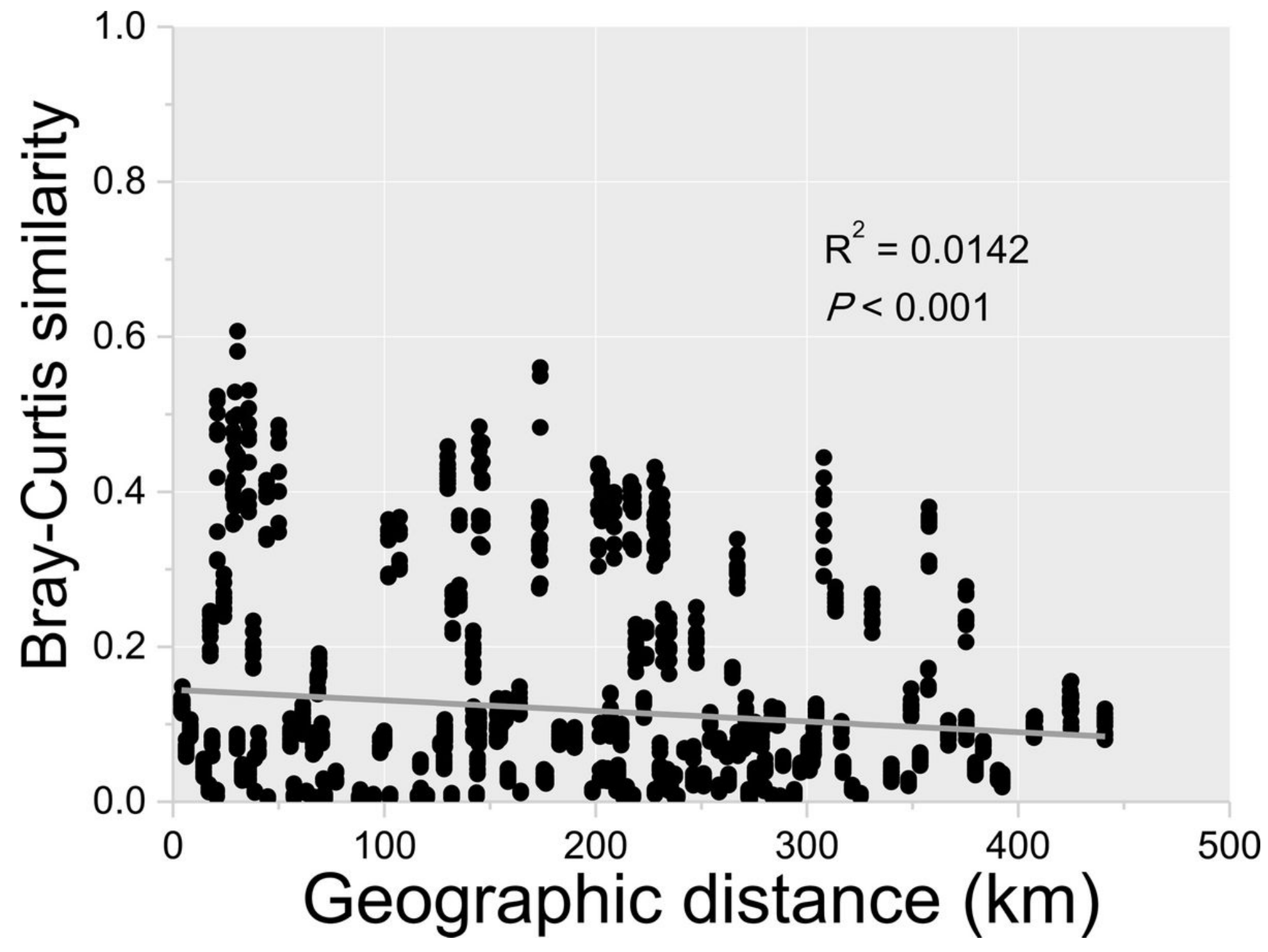

Figure 6

Relationship between the Bray-Curtis similarity of the microbial community and geographic distance between sampling stations. The solid red line indicates the fit between geographic distance and BrayCurtis similarity. 
a

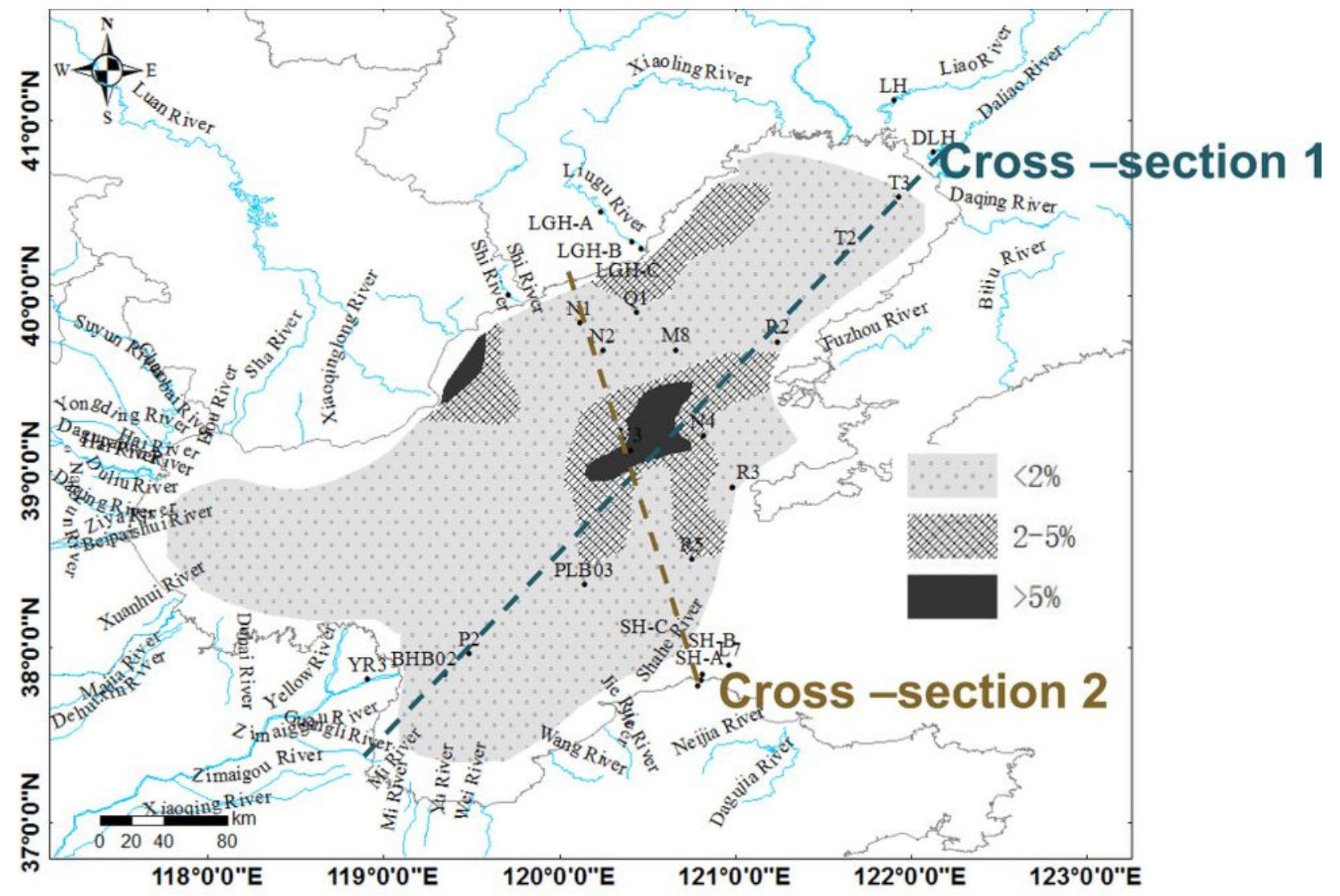

b

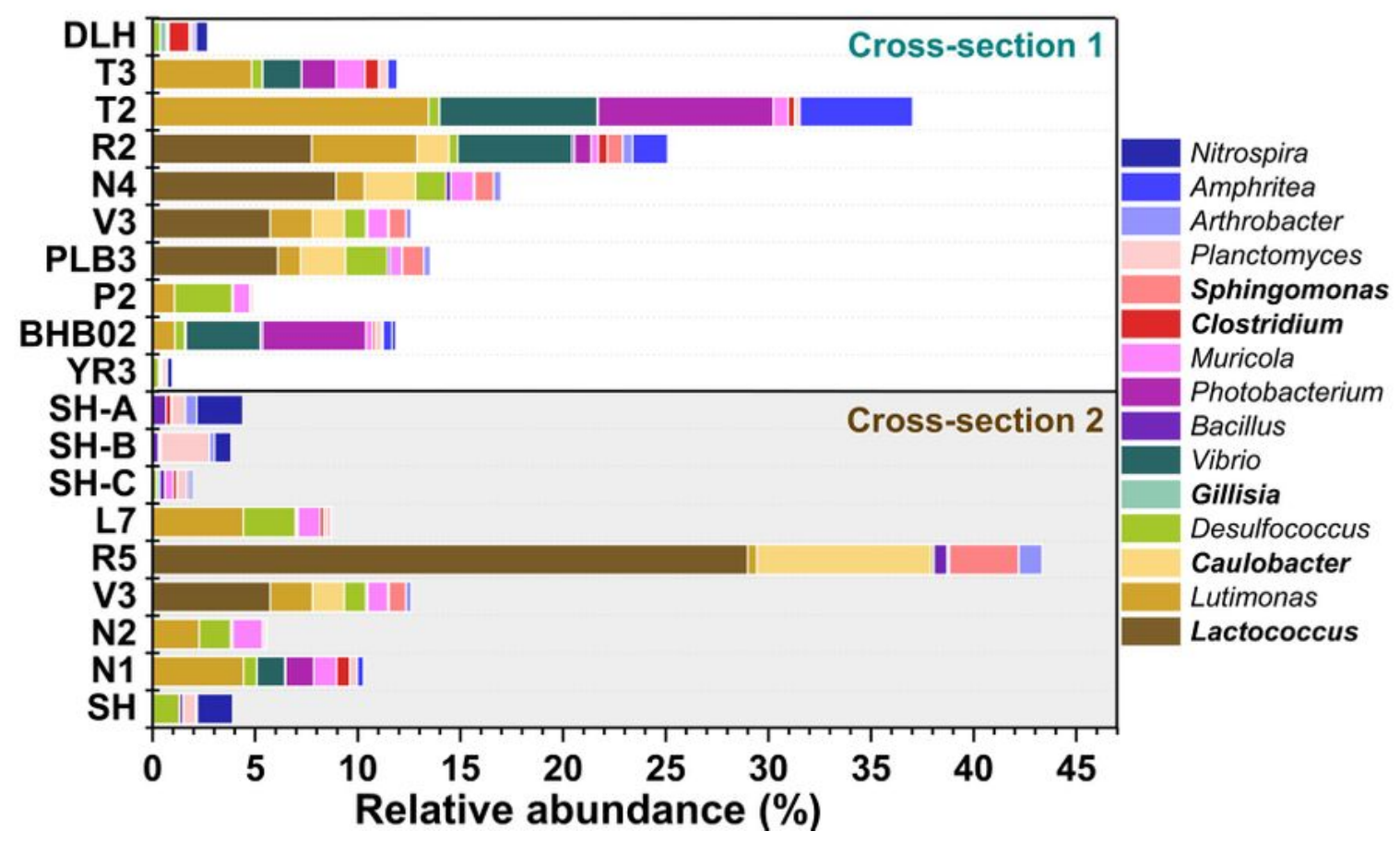

Figure 7

a Maps showing sediment sample sites from two standard oceanic sections through the Bohai Sea, section 1 (DLH, T3, T2, R2, N4, V3, PLB3, P2, BHB02, YR3) and section 2 (SH-A, SH-B, SH-C, L7, R5, V3, N2, $\mathrm{N} 1, \mathrm{SH}$ ). b Top 15 bacterial abundant genera of sample sites from two standard oceanic sections. Bold indicates the significant difference $(P<0.05)$ tested by correlation analysis between genera and geographical distance to the center of magnetite in Table 4. 
a

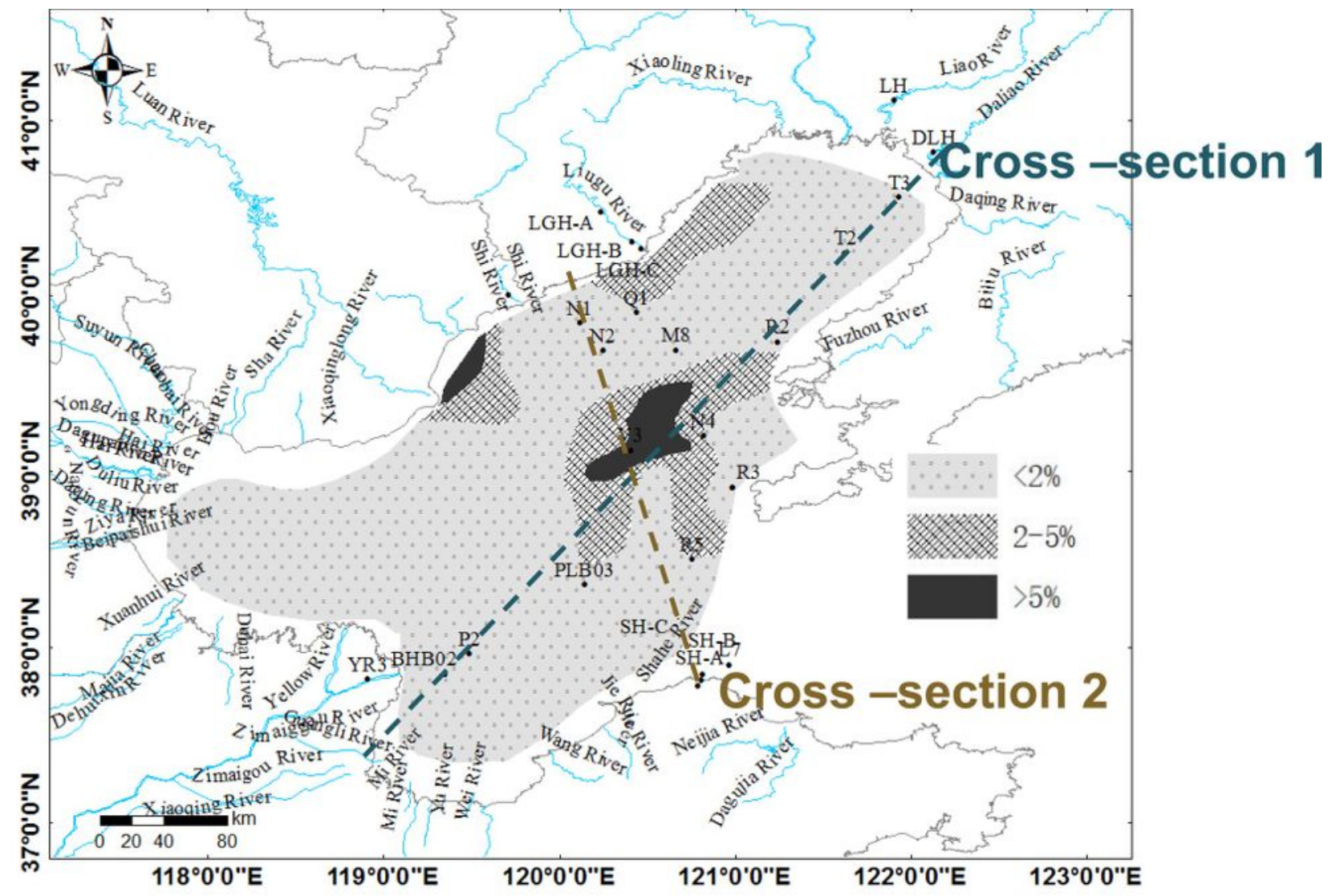

b

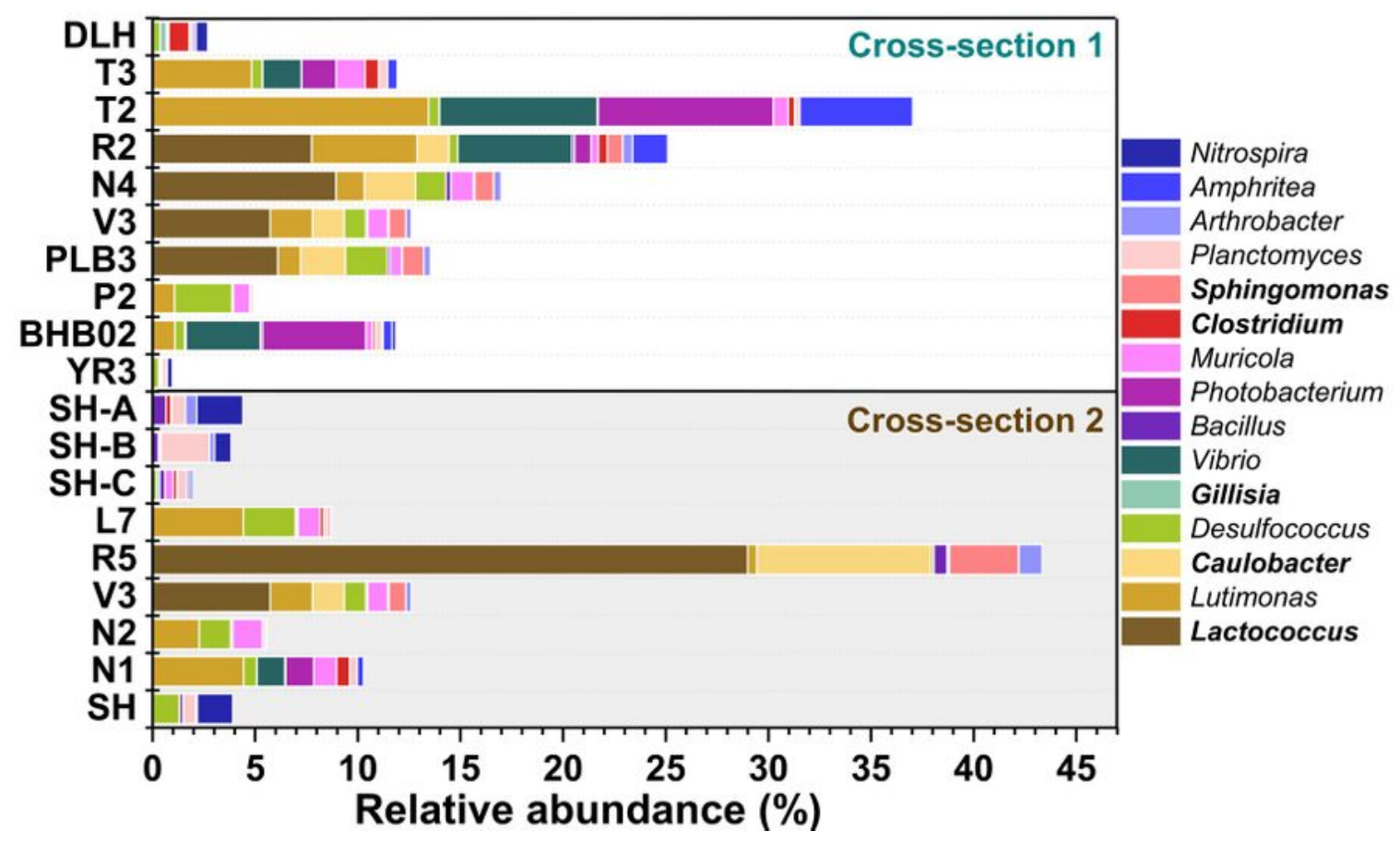

Figure 7

a Maps showing sediment sample sites from two standard oceanic sections through the Bohai Sea, section 1 (DLH, T3, T2, R2, N4, V3, PLB3, P2, BHB02, YR3) and section 2 (SH-A, SH-B, SH-C, L7, R5, V3, N2, $\mathrm{N} 1, \mathrm{SH}$ ). b Top 15 bacterial abundant genera of sample sites from two standard oceanic sections. Bold indicates the significant difference $(P<0.05)$ tested by correlation analysis between genera and geographical distance to the center of magnetite in Table 4. 


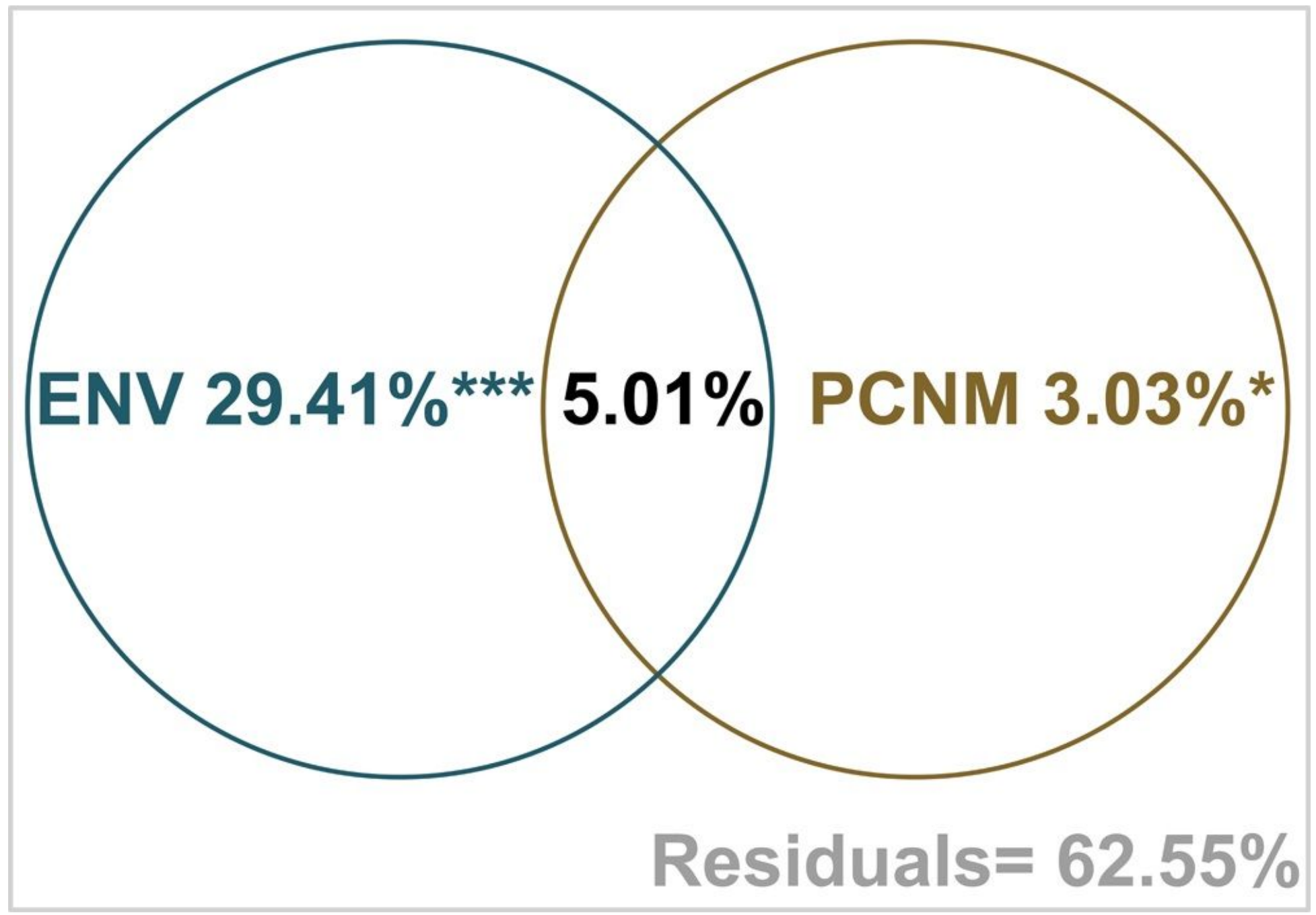

Figure 8

Variation partitioning of bacterial community composition in coastal sediments. The explanatory power of the pure and shared fractions of environment (Env), and spatial factors are indicated as adjusted R2.

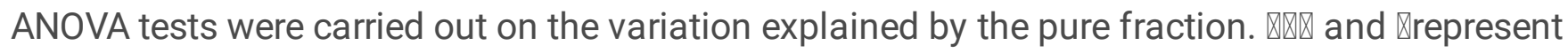
statistically significant differences of $\mathrm{P}<0.001$ and $<0.05$. 


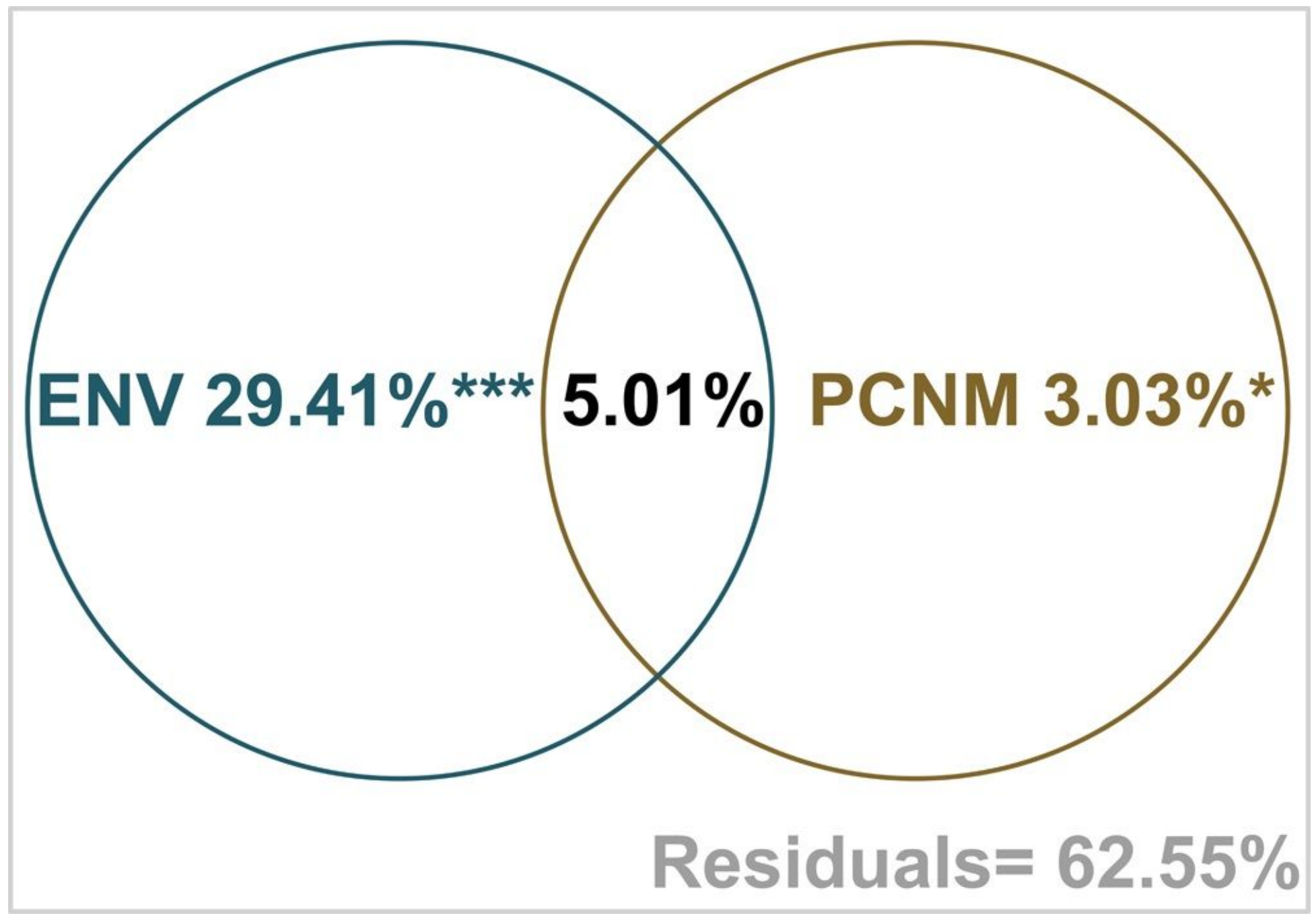

Figure 8

Variation partitioning of bacterial community composition in coastal sediments. The explanatory power of the pure and shared fractions of environment (Env), and spatial factors are indicated as adjusted R2.

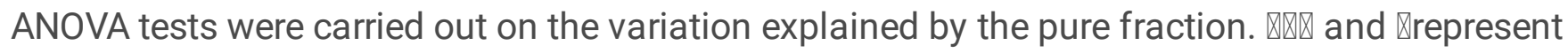
statistically significant differences of $\mathrm{P}<0.001$ and $<0.05$.

\section{Supplementary Files}

This is a list of supplementary files associated with this preprint. Click to download.

- Tables1.docx

- Tables1.docx

- Tables2.docx

- Tables2.docx 